\title{
Endoscopic Endonasal Skull Base Surgery: Current State of the Art and Future Trends
}

\author{
Jouanneau Emmanuel, Messerer Mahmoud \\ and Berhouma Moncef \\ Department of Neurosurgery \\ Skull Base Surgery Unit Pierre Wertheimer \\ Neurological and Neurosurgical Hospital \\ Lyon \\ France
}

\section{Introduction}

Endoscopic endonasal skull base surgery (EESBS) is undergoing a remarkable evolution as in the last two decades it shifted from pituitary surgery to a myriad of approaches extending from the cribriform plate to $\mathrm{C} 2$ and laterally to the petrous apex and to the infratemporal fossa. The collaboration with ENT surgeons, technological advances in the field of instrumentation and endoscopic systems, a better comprehension of the skull base anatomy as seen from below and recent innovations in reconstruction techniques have led to obvious improvements in the management of cranial base lesions. EESBS is now becoming the goldstandard approach to the sellar, retrosellar and clival regions; however, its role in the management of anterior skull base tumors is still debated.

Through their experience of more than 400 endoscopic endonasal skull base procedures, the authors expose their modus operandi and discuss the current controversies as well as future trends.

\section{A brief history of endoscopic procedures in neurosurgery}

EESBS represents the recent meeting of endoscopic techniques, developed mainly by urologists, and pituitary transsphenoidal surgery.

\subsection{First endoscopes}

Endoscopic explorations of hollow organs appeared during the 19th century. A German physician, Philipp Bozzini (1773-1809), is considered as the inventor of the first endoscope which he named "Lichtleiter" (Figure 1, left). The latter was very difficult to handle and painful for the patients. Jean Desormeaux (1815-1894), a renowned French urologist, improved Bozzini's Lichtleiter using all the advances made during the second half of the $19^{\text {th }}$ century in the fields of lighting (Castelnuovo et al., 2010a; Leger, 2004). The development of 
optic lenses led to the ergonomy optimization and the manoeuvrability improvement of endoscopes used mainly by urologists such as Max Nitze (1848-1906) (Herr, 2006; Litynski, 1999; Rathert, 1967). Paradoxically, the first ventricular neuroendoscopy with cauterization of choroid plexuses has been performed by an American urologist, Victor Darwin Lespinasse (1878-1946) (Grant JA, 1996), followed during the first half of the 20th century by Walter Dandy, one of the leading pioneers of neurosurgery (Dandy, 1926, 1932). Numerous improvements of optical systems made during the first half of the $20^{\text {th }}$ century led to the modernization of endoscopic procedures. ENT surgeons like Messerklinger, Draf and Stammberger developed these endoscopic techniques in the management of paranasal sinuses diseases (Draf, 1973; Reuter, 2000; Wigand, 1981). After being used initially for cerebral third ventriculostomy, endoscopy changed dramatically the approach to the pituitary region at the end of the last century and initiated neurosurgeons to endoscopic endonasal skull base surgery.
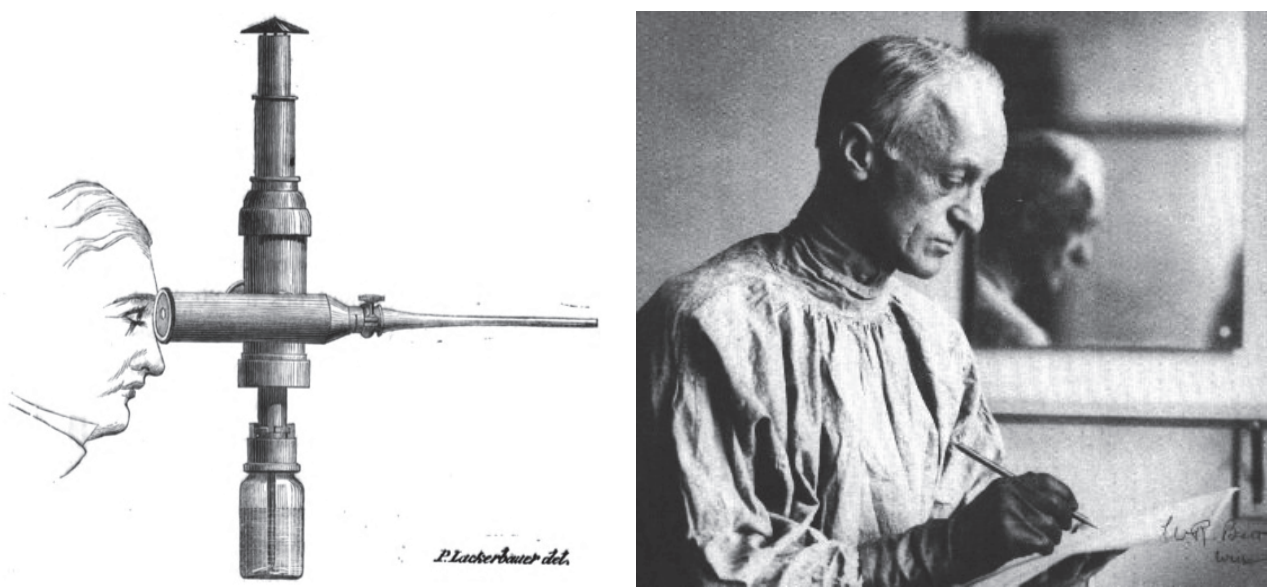

Fig. 1. Left: The "Lichtleiter", first endoscope designed by Philipp Bozzini (1773-1809)

Right: Harvey Cushing (1869-1939), the pioneer founder of the transsphenoidal pituitary surgery

\subsection{Pituitary surgery}

Modern pituitary surgery began with Harvey Cushing (Figure 1, right) during the early years of the $20^{\text {th }}$ century, with the development of the sublabial transsphenoidal approach (Figure 2) and the use of a frontal light (Cushing, 1909). The initial poor results of this technique and the reduced visualization of the sella led to abandon the transsphenoidal route in favor of the transcranial approaches (Caton, 1893; Landolt, 2001; Lindholm, 2007; Pollock et al., 2003).

Gerard Guiot induced a rebirth of the trans-sphenoidal surgery in the middle of the last century with the introduction of the peroperative fluoroscopy and he first used an endoscope within the sella (Guiot et al., 1963a, 1963b). Later, Jules Hardy normalized the current pituitary surgery practice with the use of the operative microscope (Hardy, 2010; Liu et al., 2001). The application of endoscopic techniques in pituitary surgery and then in skull 
base surgery started progressively in the late 1980's before experiencing an exponential success during the last decade (Carrau et al., 2001).
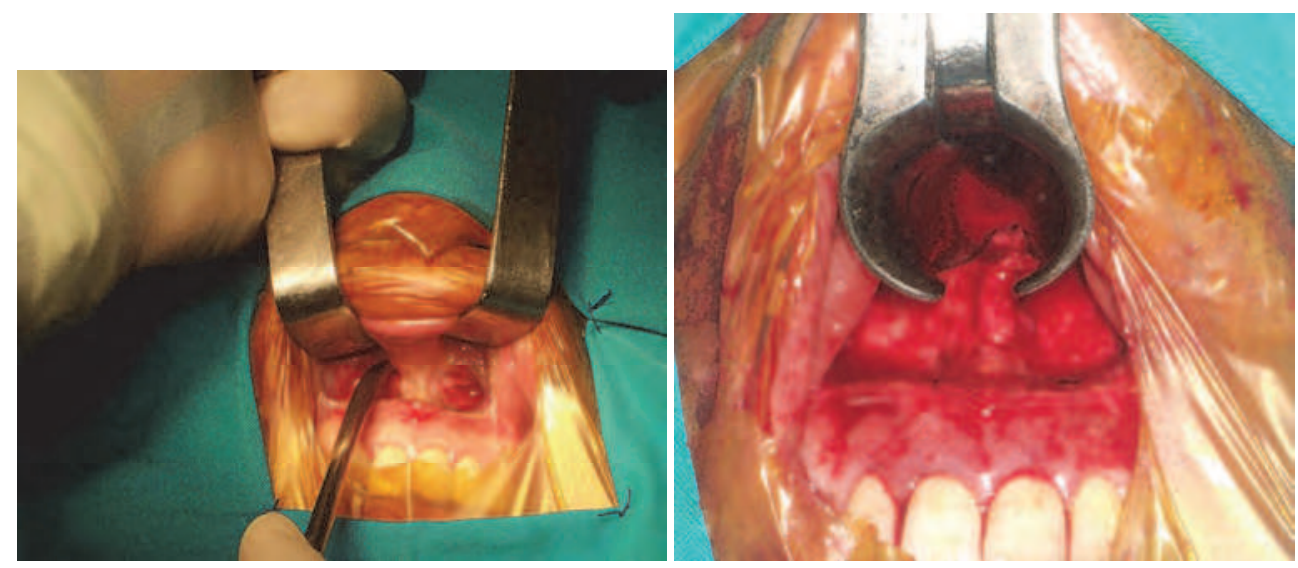

Fig. 2. Classical sublabial trans-sphenoidal microsurgical approach for pituitary adenomas.

\section{Endoscopic endonasal anatomy of the skull base}

The point of this section is to give the reader the main anatomical landmarks the surgeon has to deal with when using endonasal approach to the skull base (for more detailed and specific anatomical considerations, readers are invited to consult the references list at the end of this chapter).

\subsection{Nasal fossa}

The nasal cavity is marked medially by a rigid structure, the septum (S) (association of the perpendicular plate of the ethmoidal bone on the superior aspect, the vomer on the inferior aspect and anteriorly the quadrangular cartilage), and laterally by three longitudinal folds named the turbinates or conchae. Posteriorly both choanae $(\mathrm{Ch})$ give access to the cavum. Placed immediately at the entry and below, the first seen turbinate is the inferior turbinate (IT) attached to the ethmoidal bone. Up, above and more posterior is the middle turbinate (MT), a part of the ethmoid (Figure 3, left).

The head of the middle turbinate is free and may be pneumatised (concha bullosa) and then narrows the surgical corridor (in such cases its complete or partial resection may be required). Septal deviation or spines can also complicate the surgical approach and have to be studied scrupulously on the preoperative imaging. During the nasal step, the middle turbinate has to be pushed gently aside laterally placing a spatula up to its posterior part (Figure 3, right). Caution will be taken when mobilizing those turbinates to avoid any skull base fracture and CFS leaks. Thereafter, the superior turbinate and medially the sphenoid ostium will appear (Figure 3). This key landmark is the entry point to the sphenoid sinus, placed about one and a half centimeter above the choanae (Ch). A branch of the sphenopalatine artery, the posterior nasal artery (dotted red arrow) passes just below to the sphenoid ostium to join the septum and may be cauterized to avoid postoperative nasal hemorrhages. 


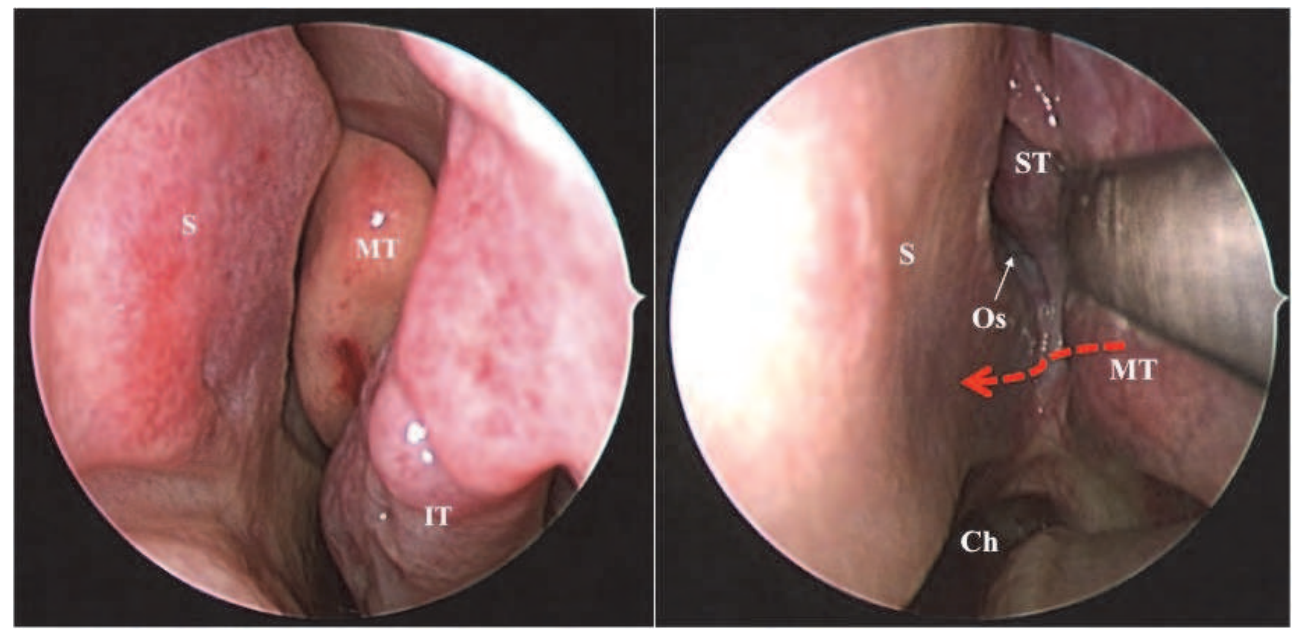

Fig. 3. Nasal step of a left endoscopic endonasal approach: Middle (MT) and inferior (IT) turbinates with the nasal septum (S) on the midline. Note the sphenoid ostium (Os) boarded by the posterior nasal branch of the sphenopalatine artery and superiorly the superior turbinate (ST)

\subsection{Sphenoid sinus}

The degrees of pneumatization of the sphenoid sinus and its septa have numerous variations which have to be studied on the preoperative MRI and/or CT-Scan. More often, the sphenoid sinus is largely pneumatized (sellar type). After removing the septa, the following landmarks are identified (Figure 4):

- Up and anteriorly the tuberculum of the sella (TS) and the planum (Planum)

- Centrally, the sella and the pituitary fossa.

- Laterally and up the optic nerve, paraclinoid carotid processes (C5) and the medial (OCR med) and lateral (OCR lat) opticocarotid recesses.

- Laterally, the anterior wall of the cavernous sinus and below the paraclival carotid processes (C3).

- Below the clivus corresponding posteriorly to the brainstem.

\subsection{Perisellar anatomy}

\subsubsection{Parasellar compartment}

Opening up laterally both sphenoid recesses gives access to the superior orbital fissure and straight below to the infratemporal fossa (Figure 5). After removing the bone, passing laterally and below to the cavernous sinus, the surgeon can get access to Meckel's cave with the V2 and V3 branches of the trigeminal nerve (Alfieri et al., 2001a, 2001b; RiveraSerrano et al., 2010).

An important key for safer surgery of this area is to perfectly control the internal carotid artery (ICA). Within a sphenoid sinus of sellar type, the paraclival segment C3 is usually directly visible into the sinus just below and laterally to the sella as shown in figure 5 . It is much more difficult to individualize the $\mathrm{C} 2$ segment of the ICA which can be retrieved following the vidian nerve in its canal (Figure 5, right) (Prevedello et al., 2010). 


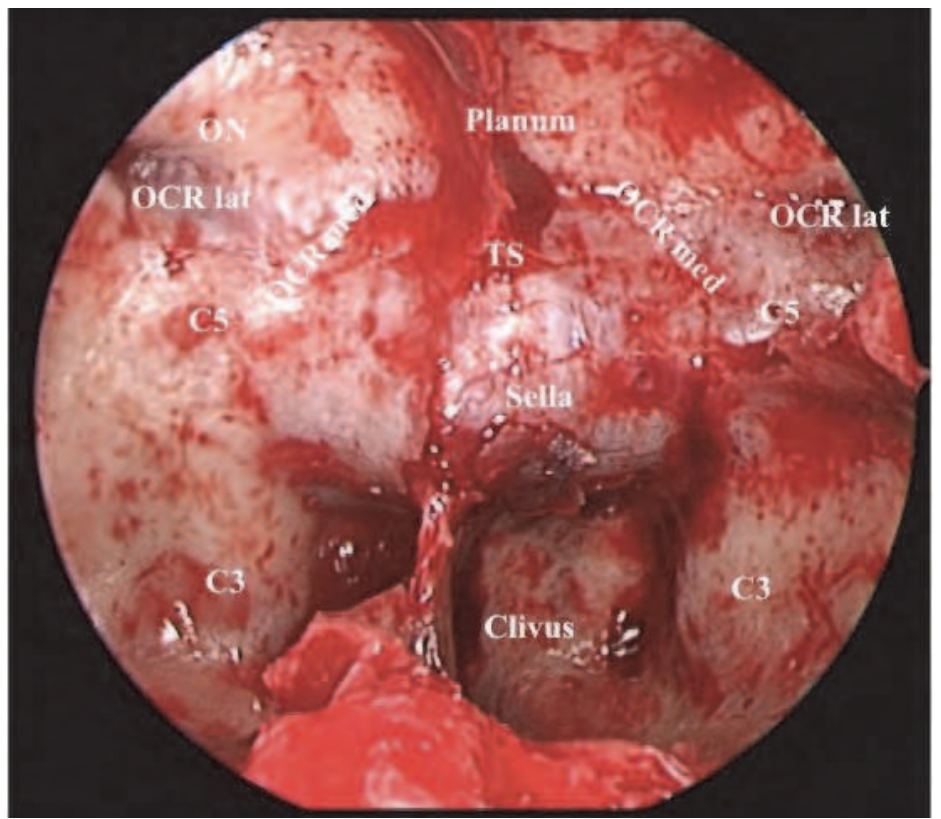

Fig. 4. Endoscopic operative view of the sphenoid sinus. Internal carotid arteries (paraclival segment C3, paraclinoid segment C5); right optic nerve: ON; Opticocarotid recesses medial (OCR med) and lateral (OCR lat).
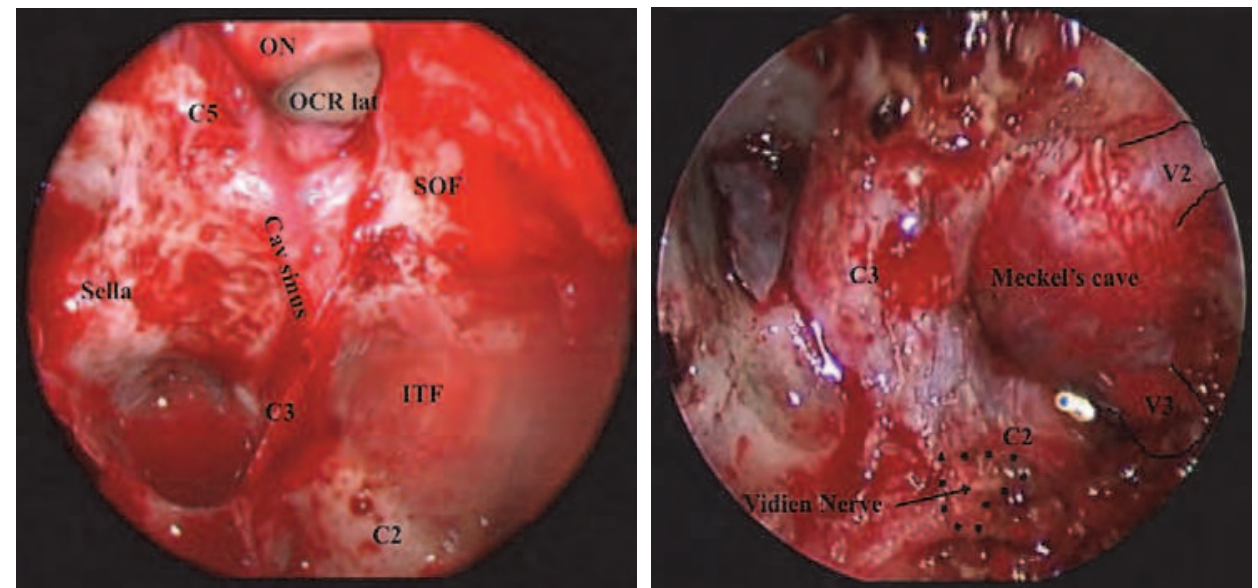

Fig. 5. Operative views of the parasellar compartment after opening the lateral sphenoid recesses.

Left (bone wall preserved): Optic nerve $(\mathrm{ON})$; internal carotid artery (ICA) paraclinoid segment C5, paraclival segment C3, petrous segment C2; lateral opticocarotid recess (OCR lat); superior orbital fissure (SOF); infratemporal fossa (ITF); cavernous sinus (Cav sinus). Right: the bone has been removed especially on the ITF exposing the Meckel's cave and the branches V2 and V3 of the trigeminal nerve. 


\subsubsection{Transplanum approach anatomy}

Opening the sella with its tuberculum and the planum provides an access to the suprasellar cistern and the optic tract. The C6 segment of the ICA and the ON will be seen laterally as well as the pituitary stalk posteriorly. Above the optic chiasm are the anterior cerebral arteries and on the midline the anterior communicating artery (Figure 6).
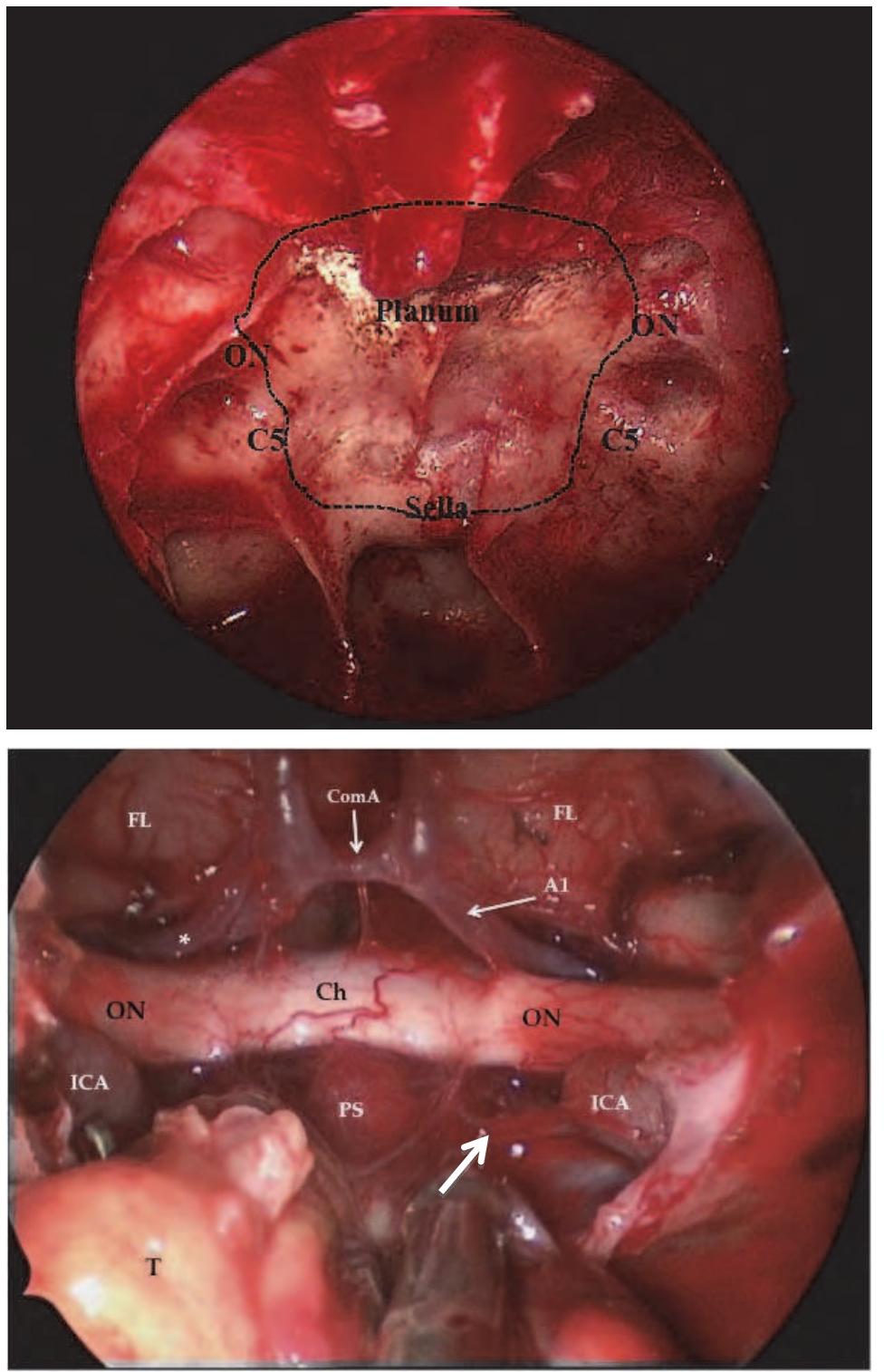

Fig. 6. Endoscopic endonasal resection of a tuberculum sellae meningioma through a transplanum transtubercular approach. 
Up: Sphenoid sinus and bone aperture (dotted line). Internal carotid artery (ICA) C5; optic nerve $(\mathrm{ON})$.

Down: Intradural dissection: meningioma $(\mathrm{T})$; optic nerves $(\mathrm{ON})$, the chiasm $(\mathrm{Ch})$, the pituitary stalk (PS), the internal carotid arteries (ICA), the A1 artery (A1) and Heubner artery $\left({ }^{*}\right)$, the anterior communicating artery (ComA) and frontal lobes (FL). A useful mark to find the PS when removing a tumor is to follow the ICA and until after the superior hypophyseal arteries (SHA, white arrow) which always lead to the PS.

\subsubsection{Transclival - transodontoid approach anatomy}

Going through the choanae and below to the sphenoid sinus (white dotted arrow, figure 7 left) gives access to the cavum. An important landmark is the Eustachian tube as the ICA passes laterally very closely (Alfieri, 2002). The mucosa can be opened as a flap that can be placed in the cavum during the surgery. After removing the lower third of the clivus bone as well as the anterior arch of $\mathrm{C} 1$ and the odontoid process, an intradural and anterior access of the brainstem is easily obtained, making the removal of lesions located in this critical area possible (Cavallo et al., 2007).

Drawing a line from the nasal bone to the palatine one (Kassam's line, orange line, figure 7 left) gives the surgeon a good evaluation of how far he can go inferiorly by an endonasal approach (usually odontoid process and upper part of C2).
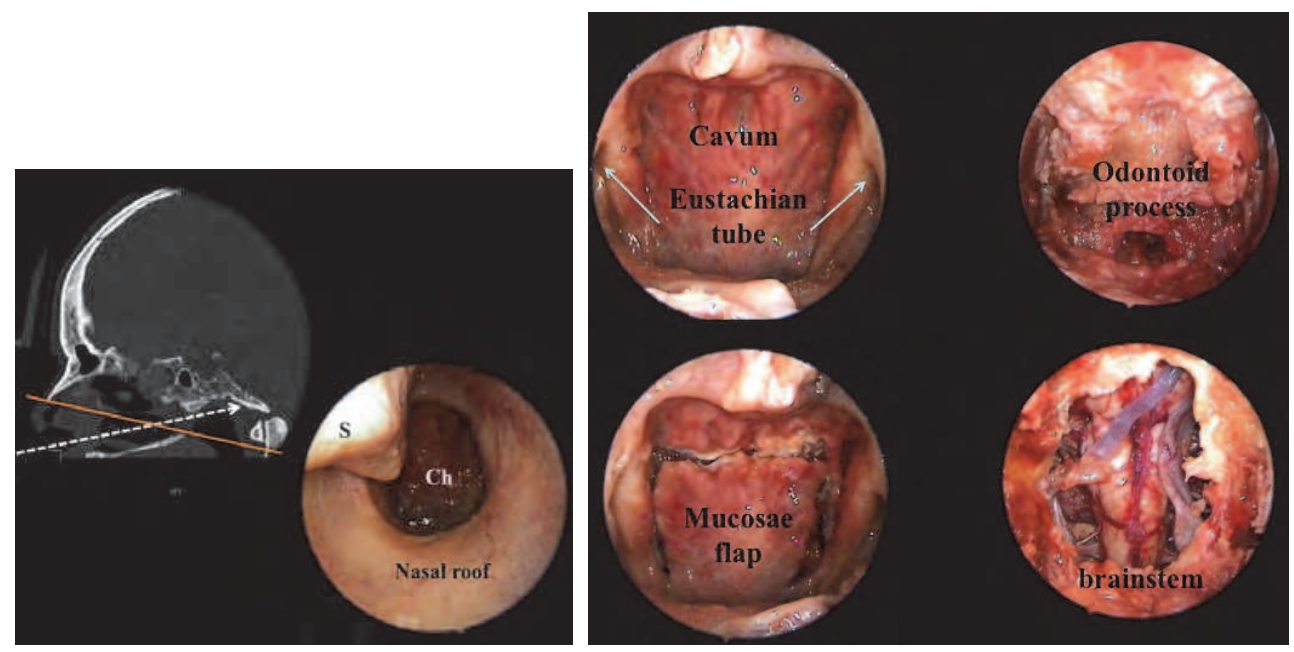

Fig. 7. Anatomic views of the endonasal approach to the clivus and cranio-cervical junction.

\section{Operative characteristics, anesthetic considerations and instrumentation}

\subsection{Preoperative protocol}

Preoperative craniofacial CT-Scan and MRI (Gardner et al., 2008) are systematically done as well as endocrinological assessment for sellar or perisellar tumors and ophthalmological examination. For cavernous sinus or Meckel's cave tumors, a cerebral angiography with occlusion tests is mandatory to avoid any unacceptable peroperative arterial occlusion in case of vascular injury during the surgery (vascular occlusion, clipping alone or associated with extra-intracranial anastomosis). 
The preoperative protocol includes polyvidone shower and nasal disinfection with polyvidone cream, the day before surgery, and also on the morning of surgery. For extended approaches, vaccines against pneumococcus, meningococcus and haemophilus are usually used to prevent postoperative meningitis risk, whenever possible.

\subsection{Anesthetic considerations}

Specific considerations for anesthesia have to be tailored to endonasal endoscopic surgery, as well as to the extent of the approach (Ramachandran et al., 2011).

Under general anesthesia, an orotracheal intubation is used, with the tube placed on the left side. Invasive blood pressure monitoring is discussed with the surgeon, depending on the invasiveness of the approach and the vascularization of the tumor.

A bloodless surgical field is of paramount importance to the neurosurgeon. Many means help to achieve this goal: preoperative planning with rigorous study of the vasculature of the tumor, which may be embolized, total intravenous anesthesia (TIVA) with propofol and short-acting opioids, the use of sympathetic blockers as hypotensive agents, the use of diluted adrenalin-soaked pledgets before endoscope introduction.

In selected cases of extended endoscopic approaches, direct submucosal infiltration with diluted adrenalin (or other vasoconstrictor) may be useful to minimize peroperative bleeding especially if a nasoseptal flap is planned.

The use of peroperative hypopharyngeal packing should be systematic to avoid the pooling of blood and to minimize the risk of postoperative vomiting related to intragastric blood accumulation.

\subsection{Dedicated instrumentation and operative room organization}

Our endonasal endoscopic technique is derived from the one described by Jho (Jho \& Carrau, 1997) and Cappabianca (Cappabianca et al. 1998).

Zero, $30^{\circ}$ and more rarely $45^{\circ}, 4 \mathrm{~mm}$ diameter rigid endoscopes are currently used during the surgery, the short one $(18 \mathrm{~cm})$ for the nasal step and the longer one $(30 \mathrm{~cm})$ during the tumor removal stage. For pediatric patients or for narrowed nostrils, small endoscopes (2.7 $\mathrm{mm}$ of diameter) have been designed.

The endoscope column is composed of a HD screen and camera, a Xenon light with an automated irrigation system to clean the endoscope during surgery without removing the endoscope.

Kassam, Cappabianca and Frank have designed dedicated sets of instrumentation (Storz $®$ ). High-speed bone drills and a mucosal automated shaver are useful. A microprobe Doppler is also used for extended approaches and for some specific pituitary surgery to localize accurately the nasoseptal flap pedicle or to individualize internal carotid arteries.

The neuronavigation system with CT-scan/MRI fusion is used for almost all our surgeries with a major role for recurrent tumors or when extended transbasal approaches have to be performed to remove intradural tumors.

The operative room organization is depicted in figure 8 . The patient is in a supine position, the trunk slightly elevated $\left(30^{\circ}\right)$ with the head flexed up and turned to the right side to face the surgeon (figure 9). We prefer to raise both the trunk and the head so that the blood accumulates into the sphenoid sinus, falling down into the cavum during surgery to improve the visualization. This position also enables a better venous drainage from the head and less peroperative venous bleeding. A real supine position is preferred for anterior skull base tumors and a more flexed position when dealing with clival tumors. 
Nevertheless, other teams work with a strict supine position whatever the type of surgery and strictly at the head of the patient. The lateral side of the right thigh is systematically draped in case of fascia lata and/or fat are needed for closure in specific cases of peroperative CSF leaks.

During the patient's positioning and after disinfection with polyvidone iodine, cotton pledgets soaked with diluted adrenalin and lidocain are placed on both nostrils. Those cottons, kept in place several minutes, allow retraction of the middle turbinate and minimize the bleeding during the nasal step.
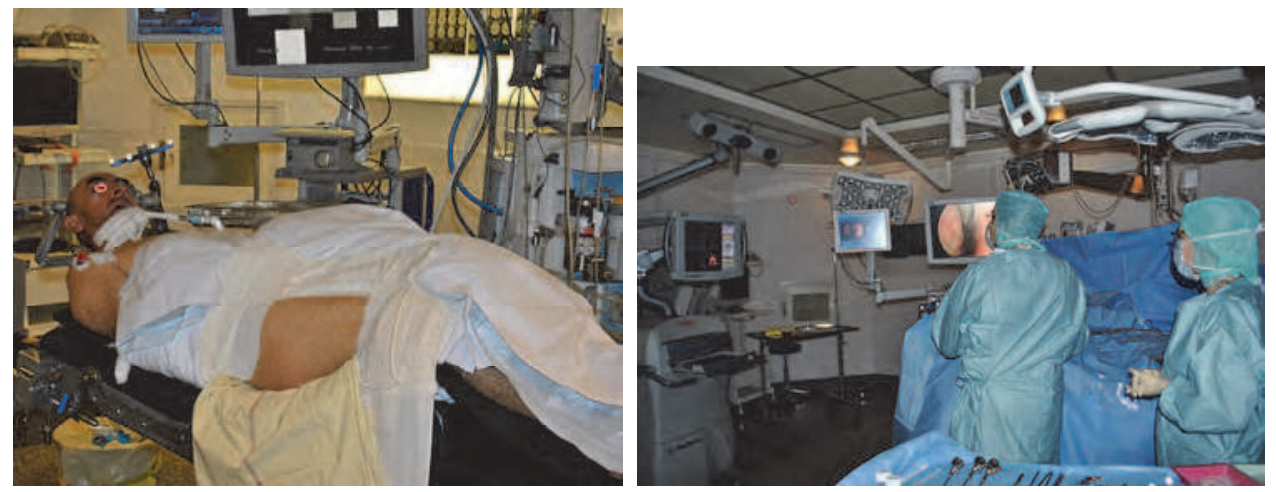

Fig. 8. Left: Patient's positioning. Right: Room organization with the neuronavigation system on the left surgeon's side and on the right the endoscopic screen. The scrub nurse is placed beside the surgeon and the anesthesiologist at the patient's left side.
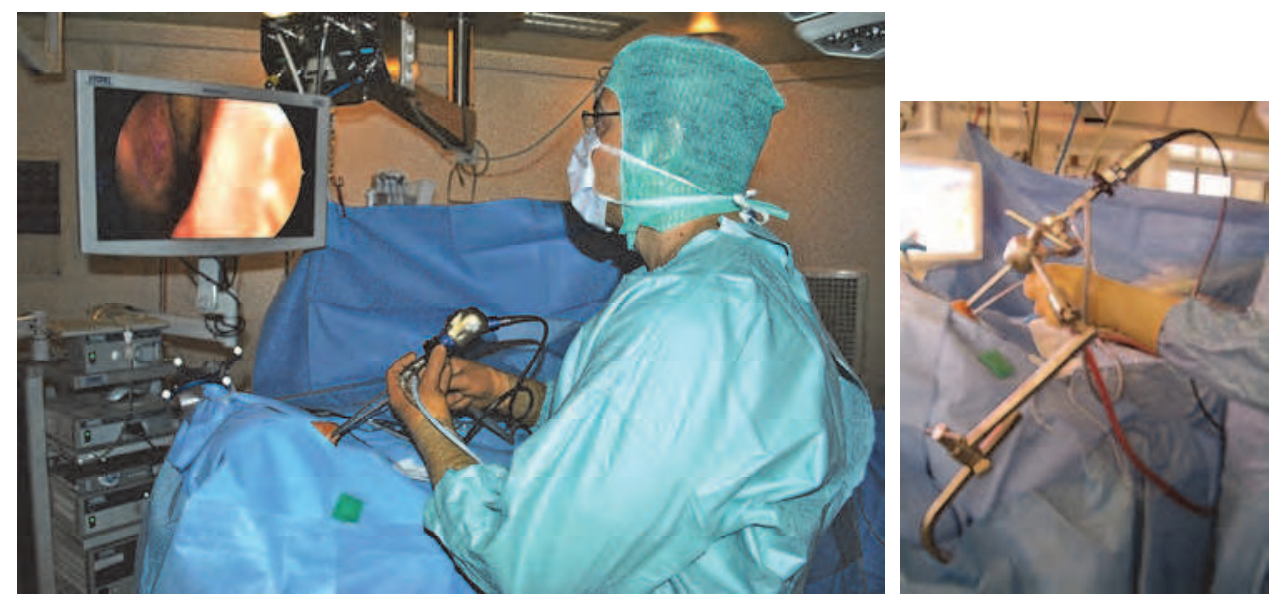

Fig. 9. Endoscope holding. Left: initial naso-sphenoidal step with a handed short endoscope. Right: Skull base opening and further steps with a rigid arm fixed to the operating table to hold the long endoscope. This allows a two hands working as with microscope. The tools are most of time introduced below the endoscope. 


\subsection{Surgical steps}

\subsubsection{Regular procedure for pituitary surgery}

The choice of the side of the nasal fossa to be used is determined by the nasal anatomy (septal deviation, megaturbinate...), lateral extension (contralateral approach to a lateral extension) and size of the tumor (binostril approach for large tumors).

In most cases of pituitary adenomas, a unilateral approach is used except for large tumors. The entire endonasal procedure until the opening of the sellar floor is performed with a hand-held short $0^{\circ}$ angle endoscope $\left(4 \mathrm{~mm}, 18 \mathrm{~cm}\right.$, Karl Storz ${ }^{\circledR}$, Tuttlingen, Germany). The superior and middle turbinates are identified and gently pushed laterally aside. It is very rare to have to remove the middle turbinate except in the case of hypertrophy as in some cases of acromegalic patient. The mucosa from the sphenoidal ostium to the choanae at the base of the vomer is coagulated and thereafter opened up pushing away the vomer until the contralateral ostium appears (figure 10). A large sphenoidotomy is performed by removing the posterior part of the vomer and the sella turcica aperture is done by performing a small bone flap from one cavernous sinus to the other, and from the tuberculum of the sella to the clivus with bone scissors (figure 11). This bone flap, kept in place at the bottom of the sphenoid sinus during the surgery, is used at the end of the surgical procedure to close the sella.

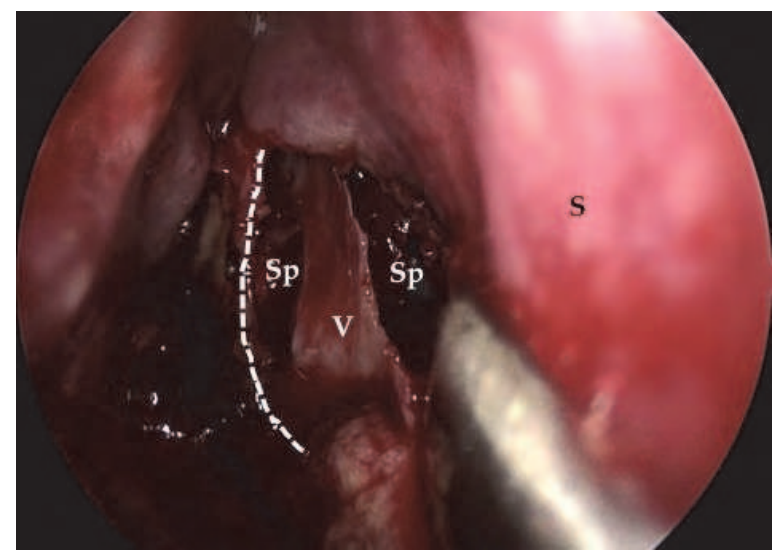

Fig. 10. Anterior sphenoidotomy via a right endonasal route. A $1 \mathrm{~cm}$ mucosa aperture (dotted white line) is done vertically after cauterization. After a sub-mucosa dissection pushing aside the bone septum (S), the vomer $(\mathrm{V})$ appears and has to be removed to achieve the opening of the sphenoid sinus (Sp).

After opening of the dura mater, a long $0^{\circ}$ endoscope $(4 \mathrm{~mm}, 30 \mathrm{~cm})$ fixed on a tablemounted endoscope holder is placed up into the nostril thus allowing the use of both hands for tumor dissection and removal (figure 9, right). The surgical tools are passed through the nose below the endoscope. Other teams work with four hands (neurosurgeon with ENT surgeon), an assistant playing the role of a smart holder. The latter can move freely to help more efficiently the operator without losing time but this needs 2 surgeons of the same level of experience, a condition not available in all institutions.

Adenomas are removed using a piecemeal technique similar to that used with microscopic surgery. In rare cases of firm adenomas, an en bloc removal with an extracapsular dissection may be used. At the end of the procedure, the sellar and suprasellar regions are explored using $0^{\circ}, 30^{\circ}$ and rarely $45^{\circ}$ endoscopes pushed up within the sella turcica (figure 11). 


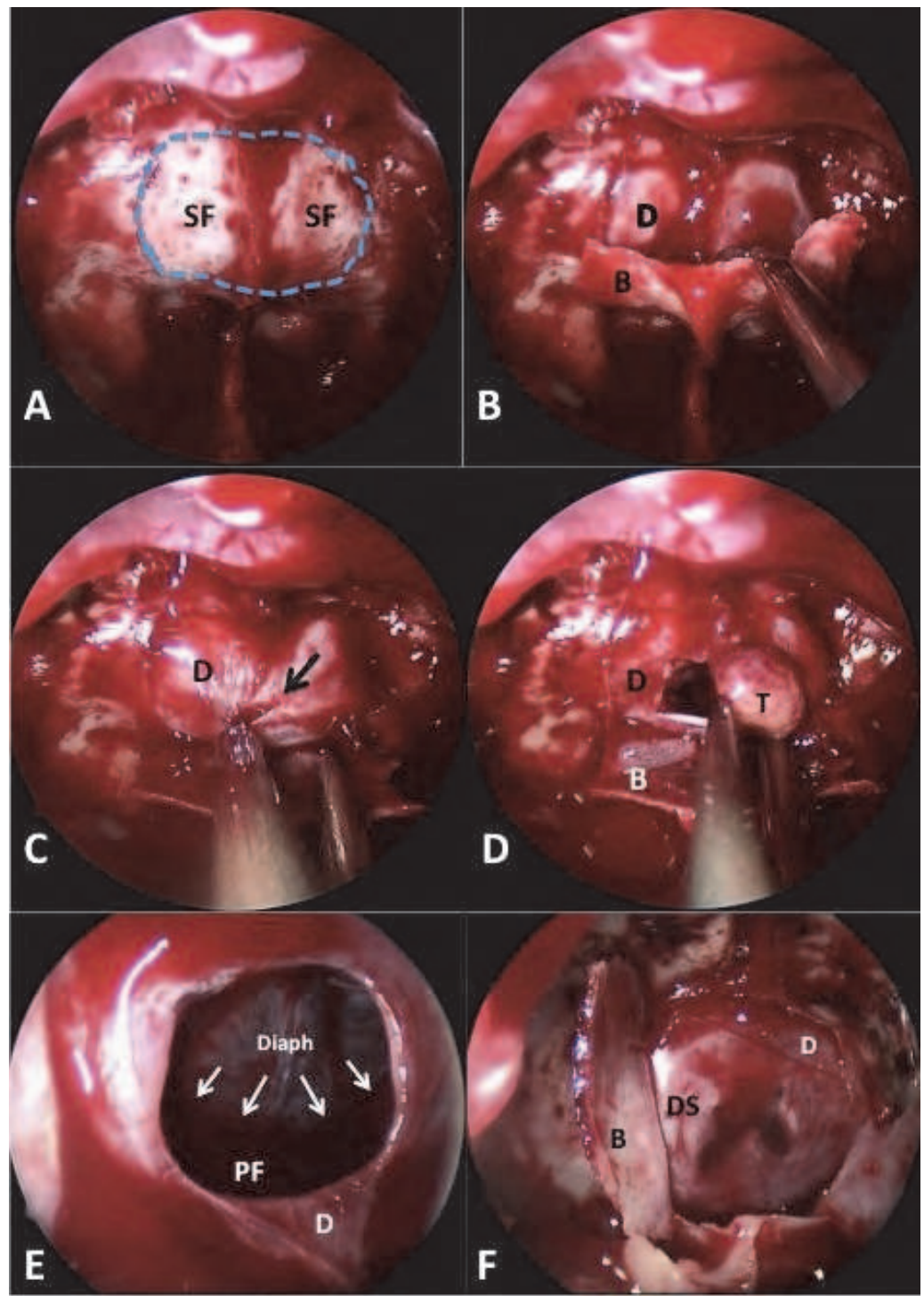

Fig. 11. Steps of the endoscopic endonasal approach to pituitary non-functioning adenoma. A: Exposition of the sphenoid sinus and the sellar floor (SF) B: Sellar floor craniotomy leaving a bone flap (B) and exposing pituitary dura (D) C: Dural (D) opening with a blade knife

D: Piece-meal removal of the adenoma $(\mathrm{T})$ with ring curettes E: End of removal allowing a drop of the sellar diaphragm (Diaph) and verification of the vacuity of the pituitary fossa $(\mathrm{PF})$

F: End of the procedure after verification of the hemostasis, interposition of dural substitute (DS) before closure of the bony sellar floor (B) 
A jugular compression is applied by the anesthesiologist at the patient's neck to detect a CSF leak before closure. Except in the case of a huge fistula, our preference is to avoid any plugging of the sella to facilitate the analysis of postoperative MRI. The closure technique did not differ from the one used during microscopic surgery with a combination of a dura mater substitute placed extradurally and covered by the bone flap embedded in fibrin glue. Should a peroperative CSF leak occurred, additional autologous material such as fat or fascia lata will be placed respectively into the sella and the sphenoid sinus with postoperative CSF lumbar drainage or puncture performed. The repositioning of the middle turbinate without any nasal packing ends the procedure.

\subsubsection{Extended approaches}

For anterior skull base tumors, a mucosa nasoseptal flap pediculated on the sphenopalatine artery or its posterior nasal branches is usually prepared and pushed down into the cavum during the surgery (Hadad et al., 2006). A Doppler probe can be used to find and keep intact the posterior nasal branches of the sphenopalatine artery which vascularize the mucosa flap. For suprasellar or retrochiasmatic tumors, an opening of the sella and the tuberculum of the sella is sufficient to expose the tumors as well as both the ICA and the optic tract. The surgeon may have to keep in mind that the wider the opening is, higher is the risk of postoperative CSF leak. We always try to perform a bone flap as we do for adenomas, to restore a rigid bone plane for the closure time. The dura mater is therefore incised on both parts of the anterior intercavernous sinus. The latter is coagulated, while small clips are placed on both extremities to prevent bleeding. The intradural time does not differ much from that of regular microsurgery.

Closure time is essential. A multilayer technique (refer to the closure paragraph), restoring all the anatomic planes, has to be done meticulously. Fibrin glue is injected onto the intradural space to seal the arachnoid. Others authors prefer to fill up the cavity with fat. Two layers of a bio-absorbable dura are thereafter placed extradurally and the bone flap flips back on the aperture sealed with fibrin glue. The mucosa flap is placed in such a manner to cover entirely the bone defect and glue is injected over to reinforce the watertight of the closure. A last layer with fat and/or fascia lata is finally used to fill up the sphenoid sinus. To prevent any layer migration during the first hours and days after surgery, an inflatable balloon can be placed inside the sphenoid sinus but only for patients who can be woken up rapidly to have their vision checked.

The same steps are respected for a transcribriform or transplanum surgery, the extension of the bone removal particularly the ethmoidectomy is dictated by the tumor extension and facilitated by the use of neuronavigation.

For parasellar approaches, after preparing the nasoseptal flap (if an intradural time or a CSF leak are expected), a lateral opening of the sphenoid sinus recess on the side of the lesion is done. The optic canal, the superior orbital fissure and orbital apex, the infratemporal fossa (behind, are Meckel's cave and the petrous apex) and medially, the cavernous sinus can be exposed, after opened up the bone, by drilling or with punches (Cebula et al., 2010). Working close to the cavernous sinus and to the Meckel's cave will require a proximal and distal control of the ICA from the C2 to the C5 segments. The C2 segment and the genu of the ICA at the foramen lacerum can be exposed following the vidian canal. 
For transclival approaches, anatomical landmarks have been described previously. A midline access from the upper clivus to the superior part of $\mathrm{C} 2$ is possible and provides a useful corridor to the tumors located anteriorly to the brainstem.

\subsection{Postoperative management}

Extended approaches with grafts and/or recovering flaps are the only approaches requiring postoperative nasal packing. The latter may be uncomfortable and painful.

If a balloon is used at the end of the surgery to maintain the grafts, it will usually be remove after 3 to 5 days, depending on the degree of skull base bone removal.

Patients are asked to avoid nose blowing as well as any activities that may raise intracranial pressure for 2 or 3 weeks after surgery and not to wash their nostrils during the first week.

To avoid germ selection, we do not give any antibiotics postoperatively whatever the type of surgery (whether extended approach or not, with or without CSF leak).

After an extended approach with CSF cisterns' opening (or after a moderate to major CSF leak during adenoma surgery), a 3 to 5 days lumbar puncture or drainage is systematically done to prevent a permanent nasal CSF fistula. The first few days after the skull base reconstruction are critical but CSF leak can be observed as much as 8 to 10 days after surgery. In our own experience, there were very few problems thereafter. Thus, the patient is usually discharged on day 4 for pituitary surgery but not before day 8 for extended approaches.

For sellar or perisellar tumors surgery, blood and urinary parameters are closely monitored for 4 days following surgery to detect diabetes insipidus. Corticosteroids hormone substitution is kept until the results of the postoperative hormonal assessment.

It may be useful to control nasal healing under local anesthesia, washing and removing crusts for 2 or 3 weeks after surgery especially for extended approaches.

\section{Classification of endoscopic endonasal approaches to skull base}

Endoscopic endonasal skull base surgery (EESBS) was initially dedicated to treat anterior and middle skull base CSF leaks, mainly by ENT surgeons but also neurosurgeons. During the 1990's, EESBS indications extended to pituitary surgery and to anterior skull base tumors, parasellar tumors and clival lesions (figure 12), shifting to what is now called extended EESBS (Kassam et al., 2006, 2007a, 2007b, 2008; Schwartz et al., 2008). Even if it is very attractive because it is considered as less invasive and adds new routes for deeply located tumors, these techniques are limited by a long learning curve (Snyderman et al., 2007, 2008) and many closure challenges.

\subsection{CSF leaks and skull base defects}

Since the publication by Dandy in 1926, in which he reported the repair of a cranio-nasal fistula through a frontal craniotomy, few advances have been described in this field, until Malte Erik Wigand, a German ENT surgeon, opened the way to endoscopic endonasal skull base fistulas' management in the early 1980's (Hirsch, 1952). Nowadays, endoscopic endonasal approach is the gold standard in this field, regarding anterior, middle or posterior skull base defects (Castelnuovo et al., 2007, 2008; Martin \& Loehrl, 2007; Nyquist et al., 2010). Closure techniques have recently benefited from biomaterial innovations (synthetic dura, fibrin glue) and pediculated flaps, and help to deal with closure issues in tumoral pathologies managed by EESBS. 


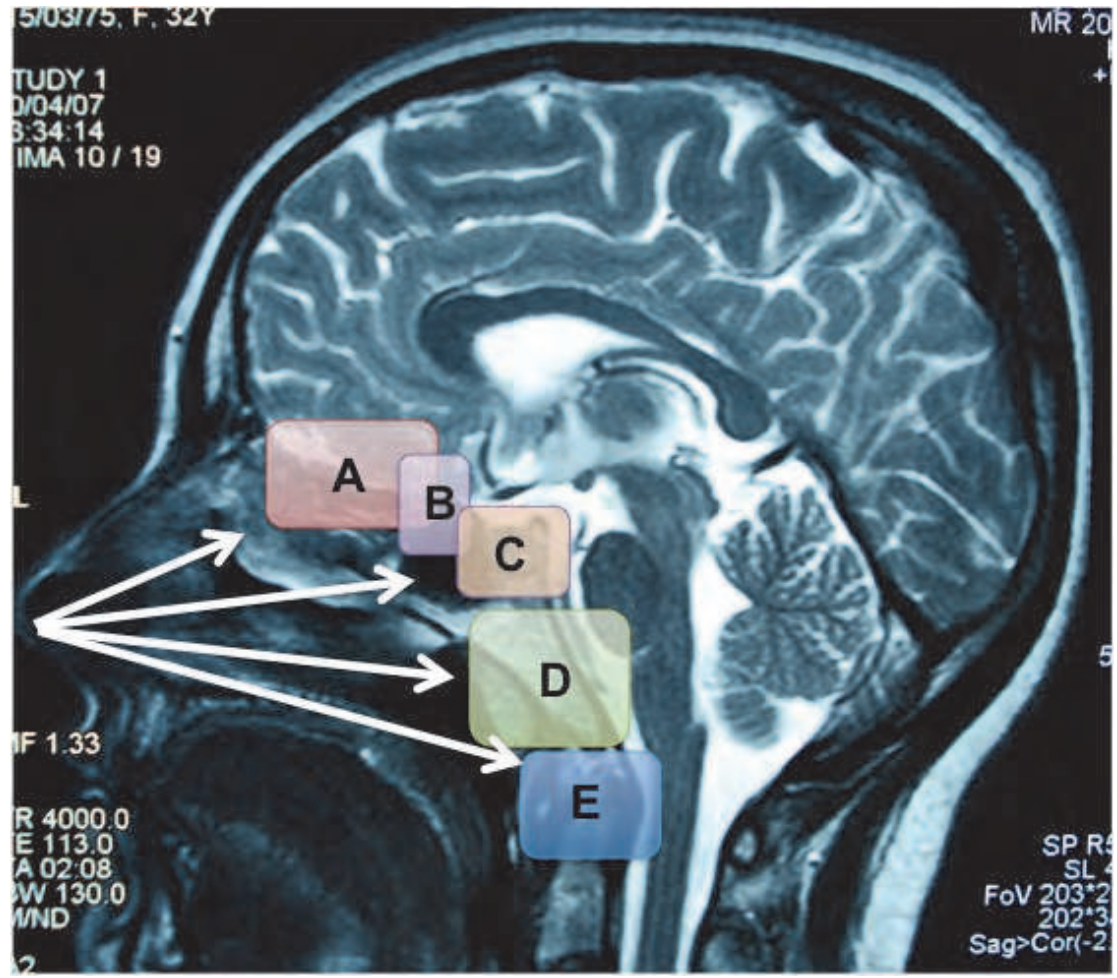

Fig. 12. Sagittal classification of endoscopic endonasal corridors.

A: Transcribriform transethmoidal

B: Transtubercular transplanum

C: Transsphenoidal sellar

D: Transclival

E: Transodontoid

\subsection{Endoscopic endonasal pituitary surgery}

The immediate position of the pituitary fossa posterior to the sphenoid sinus naturally led to the widespread use of the transsphenoidal route either by sublabial or by nasal corridors. One must keep in mind the pioneering influence of the Pittsburgh school (Jho and colleagues) and Neapolitan school (Paolo Cappabianca and colleagues) among others in the development of the endonasal endoscopic pituitary surgery during the last 2 decades (Cappabianca et al., 1998; Jankowski et al., 1992; Jho et al., 1996, 1997). Nowadays, this approach is becoming the first-line technique and most of pituitary surgeons are shifting to the endoscopic technique because of the excellent visualization of supra and para-sellar compartments it provides and a painless shorter postoperative course. Despite the absence of randomized studies proving definitely the superiority of endoscopic surgery upon microsurgery, the recent literature is accumulating evidence in favor of endoscopy especially for non-functioning pituitary adenomas (Dehdashti et al., 2008; Kassis et al. 2009 ; Frank et al., 2006, Higgins et al., 2008; Messerer et al., 2011; Schaberg et al., 2010). The rate of 
gross total removal is definitely higher in endoscopic series than in microscopic ones, for such adenomas. Data regarding functional adenomas are still debated and it seems that their results are at least comparable if not better with endoscopy (D'haens et al., 2009; Har-El, 2005).
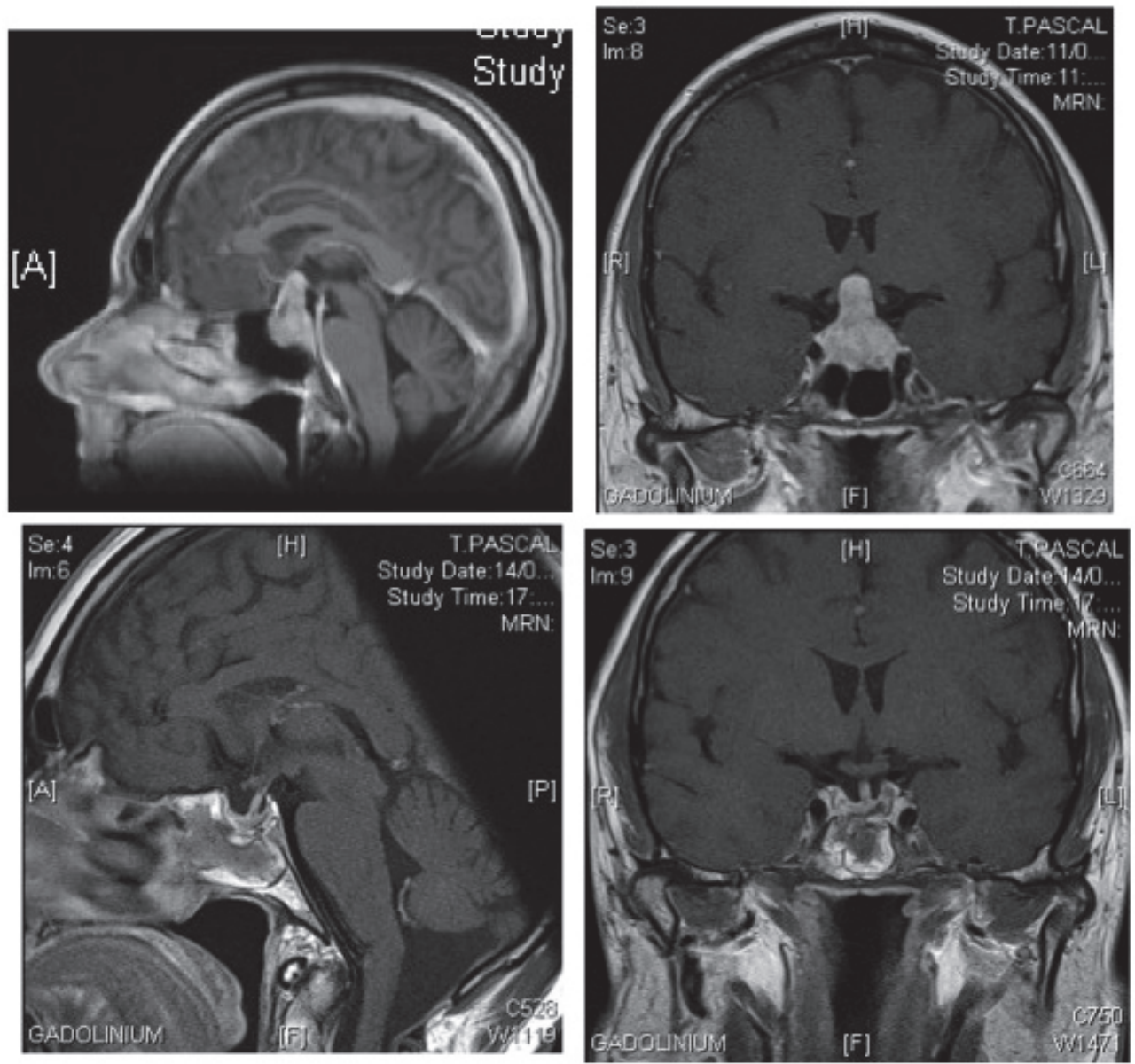

Fig. 13. Complete resection of non-functioning pituitary adenoma by endonasal endoscopic approach. Preoperative (up) and postoperative (down) MRI, T1 sequence with gadolinium.

It is important to consider that anatomic training in the lab followed by a regular practice of pituitary surgery is the first step towards endoscopic technique. The first level in the learning curve is obviously dealing with extradural cases, which have less closure and vascular issues. Surgeons will also have to learn to work with a $2 \mathrm{D}$ system and to watch a screen. After having gathered enough experience, (roughly more than 100 cases of endoscopic pituitary surgery according to almost all the renowned endoscopic experts), the training of the surgeon will enable him to perform further operations such as intradural works and extended approaches (Snyderman et al., 2007). 


\subsection{Extended endoscopic endonasal surgery}

\begin{tabular}{|c|c|}
\hline Anterior skull base & $\begin{array}{l}\text { Olfactory groove meningioma } \\
\text { Planum sphenoidale meningioma } \\
\text { Tuberculum sellae meningioma } \\
\text { Ethmoidal carcinoma } \\
\text { Nasopharyngeal fibroma } \\
\text { Esthesioneuroblastoma }\end{array}$ \\
\hline Sellar and suprasellar regions & $\begin{array}{l}\text { Diaphragm sellae meningioma } \\
\text { Pituitary adenomas } \\
\text { Craniopharyngiomas } \\
\text { Rathke cleft cyst } \\
\text { Inclusion tumors (epidermoids, dermoids, } \\
\text { teratomas) } \\
\text { Germinal tumors } \\
\text { Suprasellar tumor, "(biopsy)" }\end{array}$ \\
\hline Meckel's cave & $\begin{array}{l}\text { Chondrosarcoma and Chondroma } \\
\text { Trigeminal schwannoma } \\
\text { Metastasis (biopsy in case of doubt) }\end{array}$ \\
\hline Cavernous sinus & $\begin{array}{l}\text { Extension of pituitary adenoma or of others soft } \\
\text { tumors such as chondrosarcomas } \\
\text { Meningioma or metastasis (biopsy in case of doubt) }\end{array}$ \\
\hline Orbital apex and optic canal & $\begin{array}{l}\text { Orbital tumor located medially to the optic nerve } \\
\text { (biopsy or resection) } \\
\text { Exophtalmos } \\
\text { Canal optic decompression }\end{array}$ \\
\hline Petrous apex and clivus & $\begin{array}{l}\text { Chordoma } \\
\text { Chondroma and chondrosarcoma } \\
\text { Epidermoid cyst } \\
\text { Meningiomas }\end{array}$ \\
\hline Anterior craniocervical junction & $\begin{array}{l}\text { Rheumatoid pannus } \\
\text { Spondylodiscitis } \\
\text { Malformative anomaly } \\
\text { Bone tumors } \\
\text { Chordoma }\end{array}$ \\
\hline
\end{tabular}

Table 1. Topographical classification of skull base lesions accessible to EESBS

\subsubsection{Anterior skull base neoplasms}

Meningiomas remain the more frequent neoplasms in this region, arising between the crista galli process and the tuberculum of the sella (Fernadez-Miranda et al., 2009). Herein, the true advantages of EESBS are to provide a direct devascularization of the tumor 
(cauterization of anterior and posterior ethmoidal arteries) and avoid any retraction of the frontal lobes. The limits are detailed further in the controversies' discussion and include a high risk of fistula, a higher risk of olfactory nerves injury and a lower control of the lateral margins of the tumor. For such a location, intracranial mini-invasive keyhole approaches represent serious alternatives.

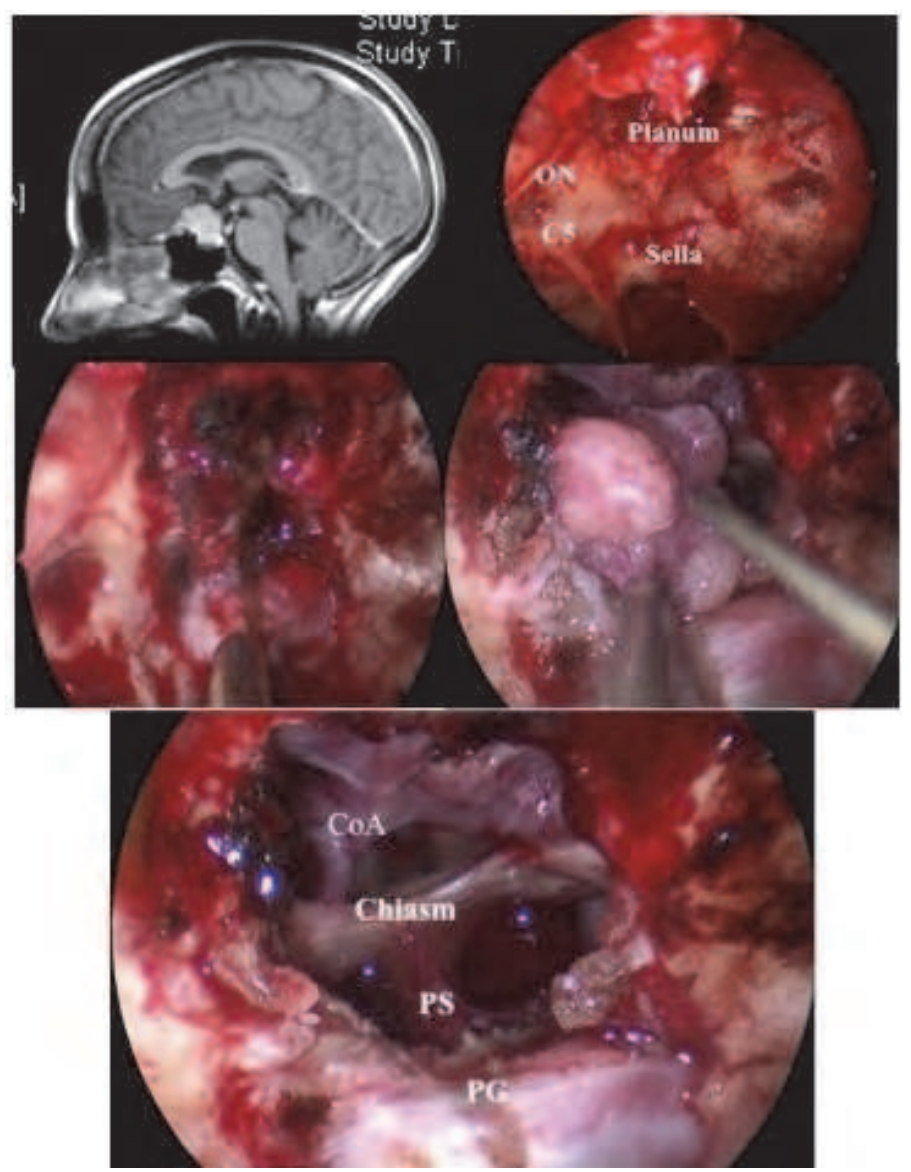

Fig. 14. Endonasal endoscopic resection of planum sphenoidale meningioma by a transtubercular approach. A one and half centimeter bone window is done with bone punch or by drilling to remove the roof of the sella, the tuberculum of the sella and the adjacent planum. After coagulation of the insertion basal dura, this latter is resected and the meningioma is progressively debulked and dissected from critical neurovascular structures (ON: optic nerve; Chiasm; CoA: anterior communicating artery; PS: pituitary stalk; PG: pituitary gland).

Many other neoplasms involving the anterior skull base have been approached through the endonasal route such as esthesioneuroblastomas (Suriano et al., 2007), nasopharyngeal fibromas and carcinomas (Batra et al., 2005). 


\subsubsection{Sellar and suprasellar non-adenomatous tumors}

Endoscopic endonasal route has been naturally and progressively applied to the suprasellar lesions (craniopharyngiomas (Cavallo et al., 2009; Gardner et al., 2008a, 2008b), Rathke cleft cyst (Alfieri, 2002), epidermoid cysts, teratomas, etc,) with an obvious absence of frontal lobe retraction and a better corridor to the retro-chiasmatic region (de Divitiis et al, 2002). An approach from below provides a direct view of the tumor and its extension into the third ventricle (figures $15 \& 16$ ). Soft or non-adherent tumors can be more completely removed under direct visualization, what cannot be done through the intracranial route. However, identifying the tumor extension does not involve its systematic removal. Tumors adherent to the third ventricle like some craniopharyngiomas have to be kept in place considering the important risk of poor postoperative outcome.

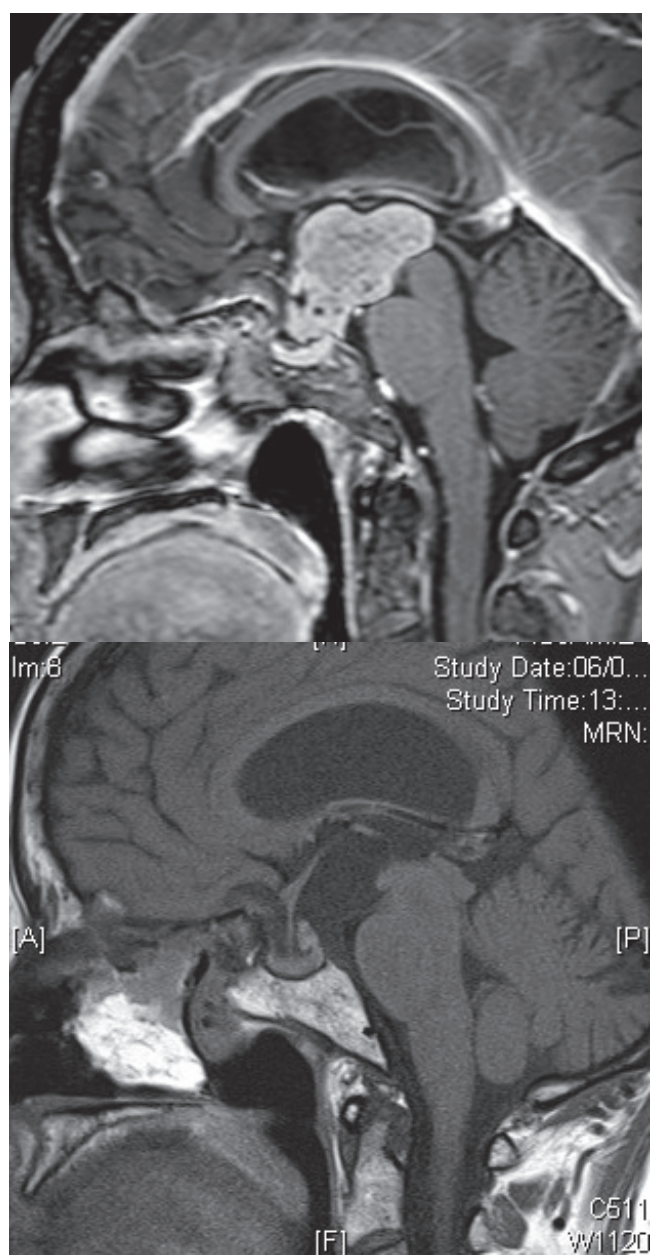

Fig. 15. Resection via an endoscopic endonasal approach of a retrochiasmatic and intraventricular suprasellar epidermoid cyst. Preoperative sagittal T1 gado MRI (left), postoperative control (right) with uneventful postoperative course. 


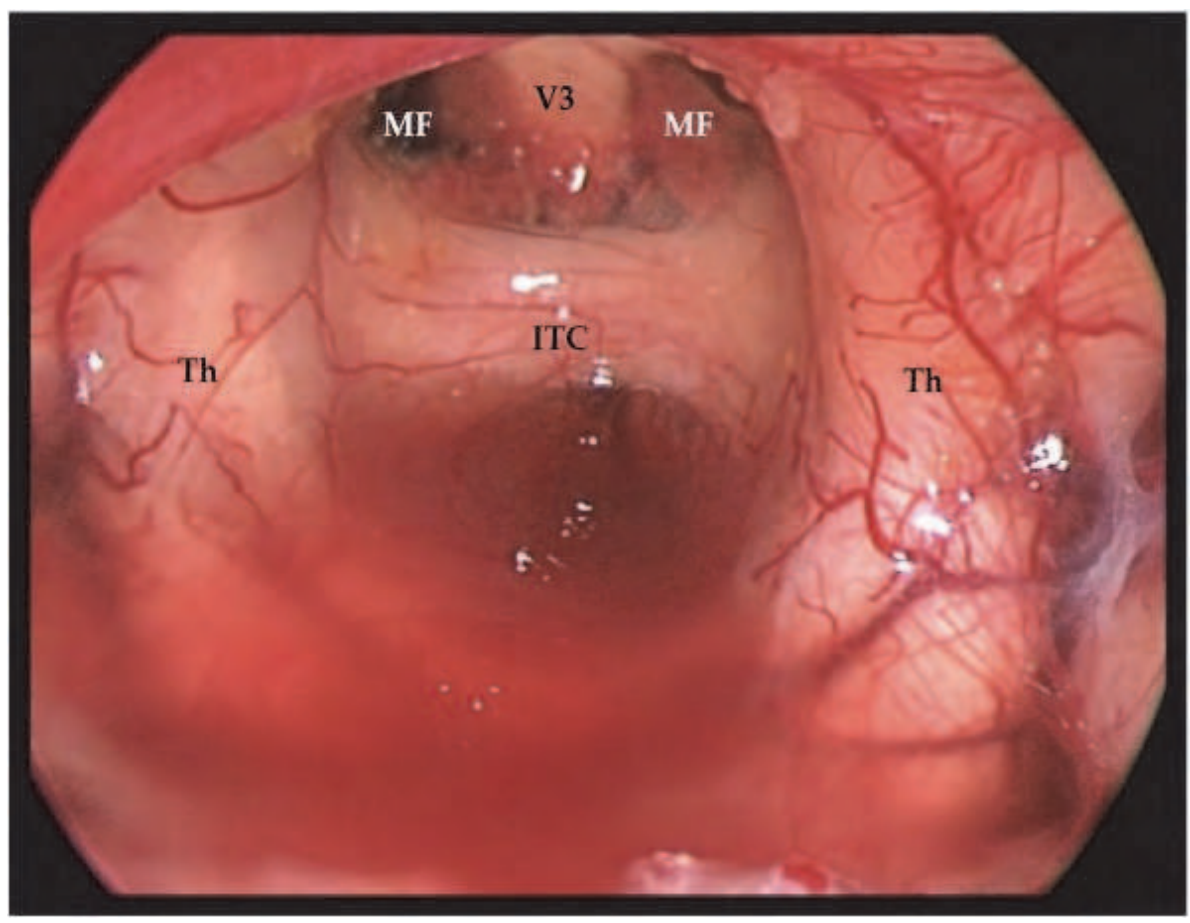

Fig. 16. Same patient as in figure 15. End of the resection showing the cavity of the $3^{\text {rd }}$ ventricle, its roof (V3), both Monro foraminas (MF), and the 2 thalami bridged by the interthalamic commissure (ITC).

\subsubsection{Meckel's cave tumors}

Mainly represented by trigeminal shwannomas (figure 17), their approach requires classically an extensive orbitozygomatic frontopterional craniotomy. Meckel's cave can be approached by EESBS through its anterior aspect laterally to the para-clival portion of the internal carotid artery (Kassam et al., 2009). By this route, we can either remove the tumor or take a sample for a biopsy, the main advantage being not crossing cranial nerves, usually pushed laterally when the tumor grows.

\subsubsection{Cavernous sinus lesions}

There are very few indications of direct surgery for cavernous sinus tumors. Primarily represented by meningiomas, the current strategy is to treat them with radiotherapy or radiosurgery, when imaging is typical. However, when some soft tumors project into the cavernous sinus such as adenomas or chondrosarcomas, the panoramic view offered by the endoscopic endonasal route allows us to complete the removal safely. In our own experience (112 cases of pituitary adenomas extending into the cavernous sinus), the endoscope allowed us to cure more than one third of functioning or non-functioning adenomas without additional morbidity (figure 18). This route can also be used for biopsy when there is any doubt about the nature of a cavernous disease. 

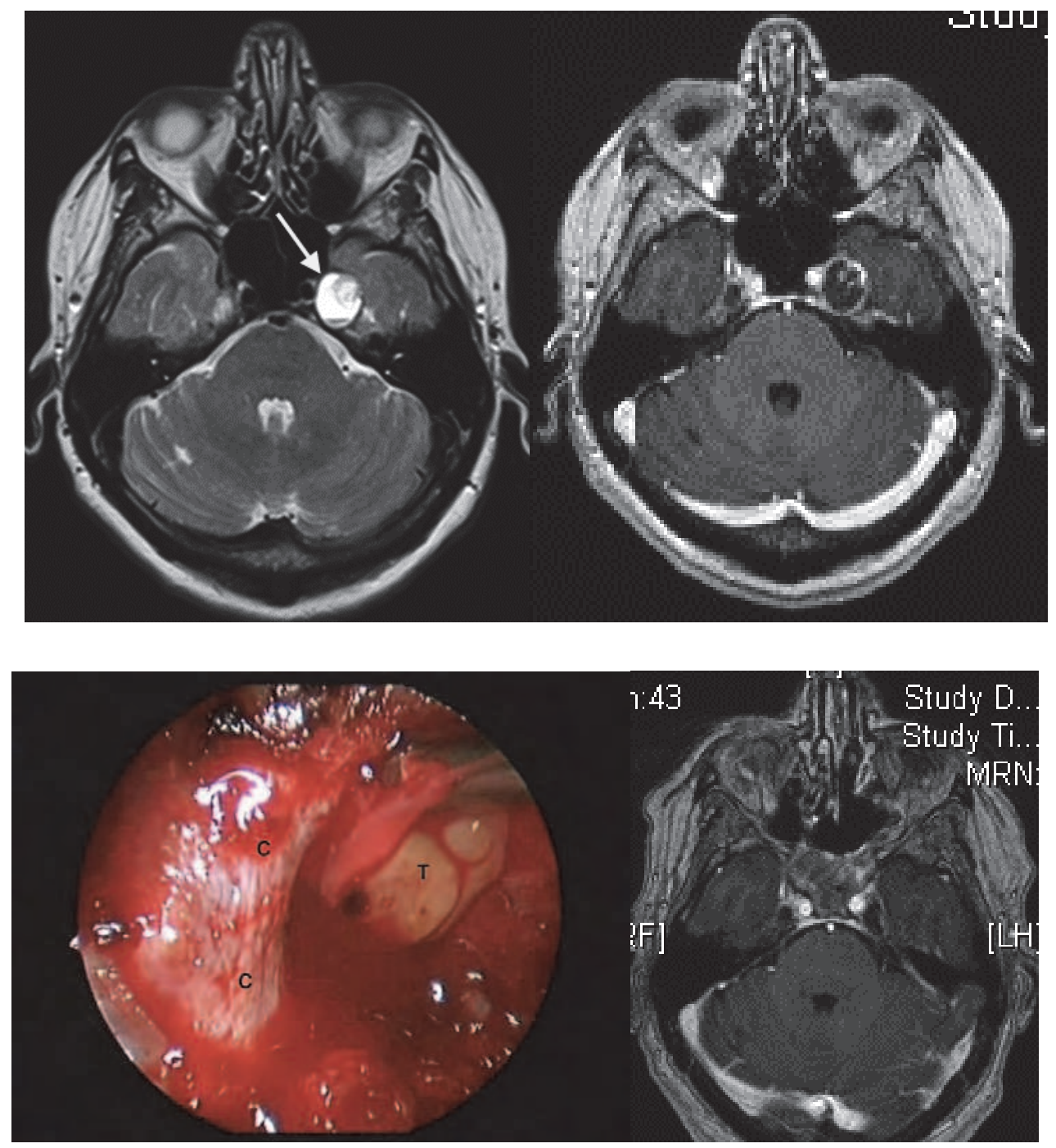

Fig. 17. Removal of a trigeminal schwannoma by an endoscopic endonasal approach. Top pictures, axial T2 and gadolinium T1 MRI showing a partially cystic tumor. Anterior approach of Meckel's cave with on the medial and the inferior side respectively the C3 and C2 portion of the ICA (C) and a typical aspect of a schwannoma (T) (down left picture). Down right: the postoperative MRI that shows a complete removal. 


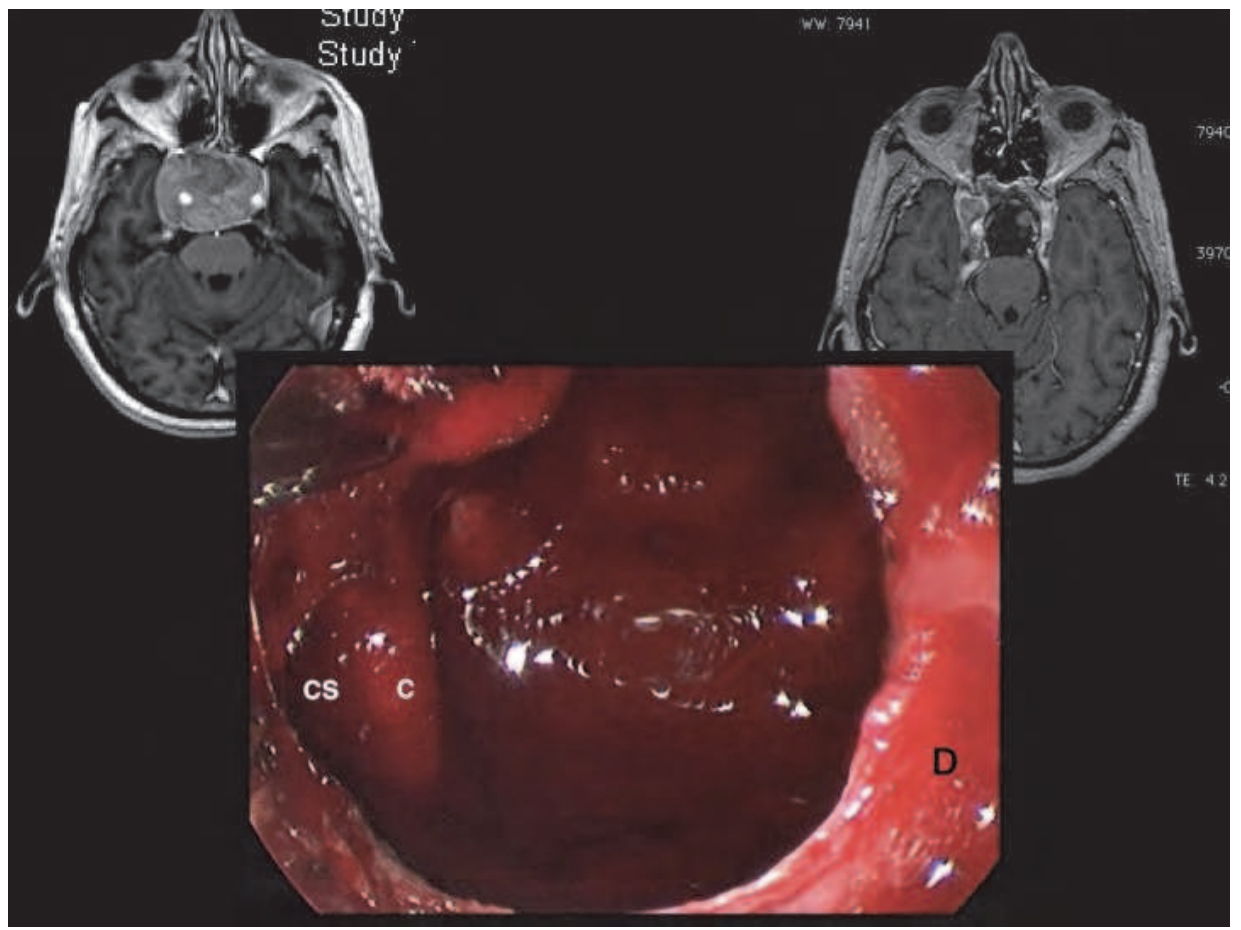

Fig. 18. Giant non-functioning adenoma invading the right cavernous sinus operated with a pure endoscopic endonasal approach (top left). During the surgery with a $30^{\circ}$ angle endoscope pushed at the entry of the pituitary fossa (D), the cavernous portion of the carotid (C) was clearly seen with a perforation on the cavernous sinus wall (CS). Under visualization and with a two suction technique, a large part of the cavernous portion of the adenoma was removed without additional morbidity. The remnant tumor is therefore minimized and accessible to radiotherapy (top right).

\subsubsection{Petrous apex and clival tumors}

Petrous apexes as well as clival tumors are very challenging lesions because of their deepness and their neurovascular environment. EESBS provides a direct access to such tumors replacing progressively the traditional subtemporal, transpetrosal or retrosigmoid approaches (Griffith \& Terrel, 1996; Kassam et al., 2005). Combination of both endonasal and intracranial procedures may be performed depending of the tumor conformation (figure 19).

\subsubsection{Anterior craniocervical junction}

Midline anterior lesions are good candidates for a direct approach by an endonasal endoscopic route, as standard far lateral approaches require crossing nerves and vessels before reaching the tumor. Rheumatoid pannus are fortunately rare with modern treatment but endoscopic endonasal resection has been described in the literature (Nayak et al., 2007). Skull base malformative anomalies and tumors can also be more easily approached through the endonasal route (Leng et al., 2009; Magrini et al., 2008). 


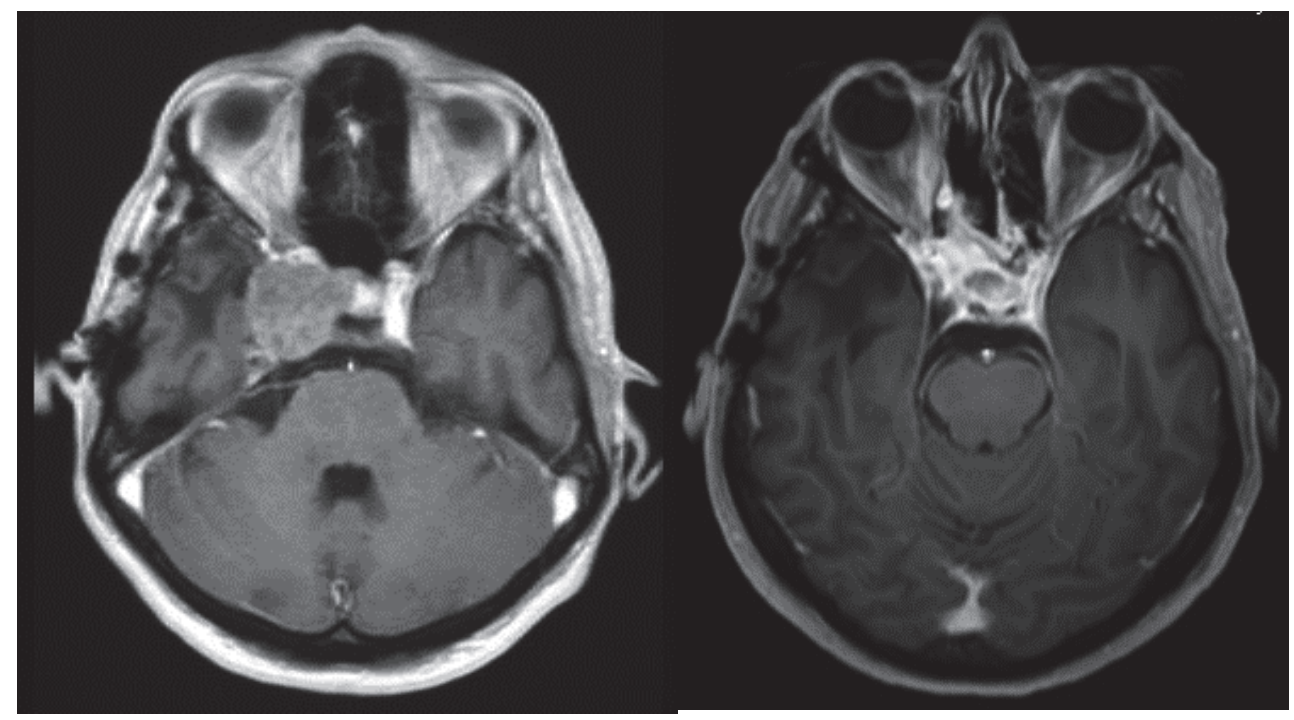

Fig. 19. Left: Petrocavernous chondrosarcoma operated on first via a subtemporal approach with a cavernous sinus tumor remnant. Right: A second step via a transsellar endonasal approach completed the removal without any postoperative cranial nerve or pituitary deficit.

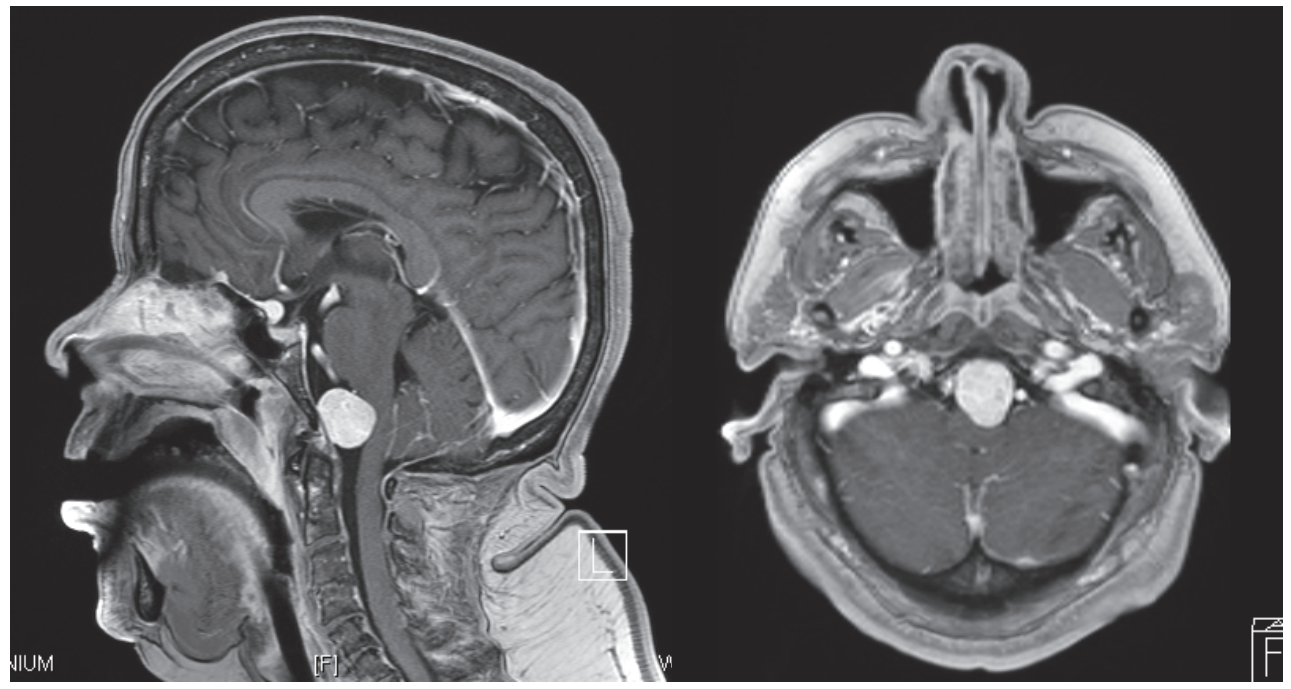

Fig. 20. Example of an anterior midline craniocervical meningioma that would be a good candidate for an endonasal endoscopic surgery because situated above the Kassam's line. 
Drawing a line from the nasal bone to the palatine bone will help the surgeon to visualize the inferior limits of the surgical field (de Almeida et al., 2009). The endonasal route usually gives access to the odontoid and the upper third of C2 (figures $20 \& 21$ ). A lesion located inferiorly is an indication of a transoral surgery where the endoscope can also be useful as the surgical field is deep and narrow (Crockard, 1985).

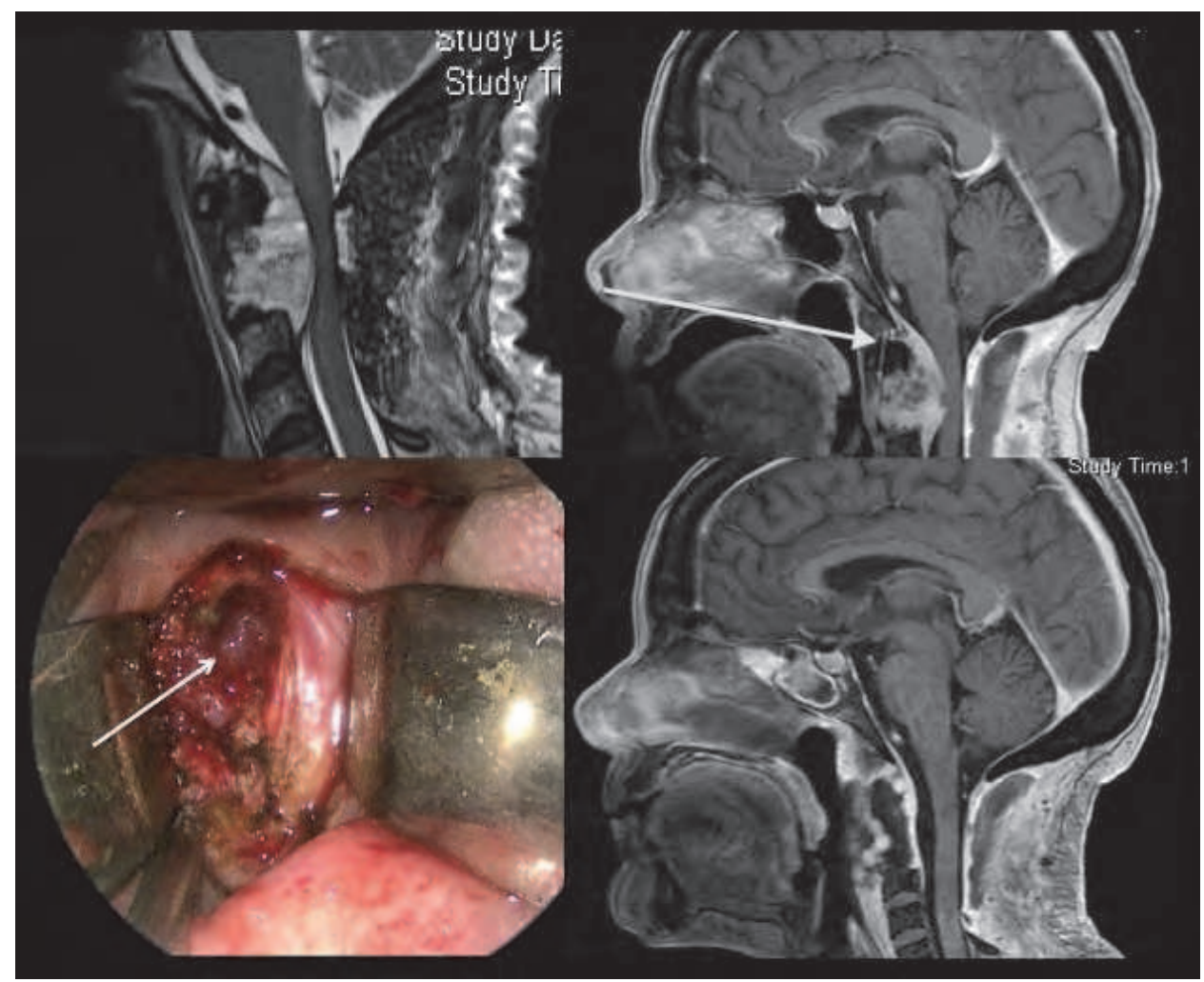

Fig. 21. Example of a C2 chordoma (top left). The tumor is located below Kassam's line indicating a transoral approach instead of the endonasal route (top right). The endoscope is a vast improvement on the microscope and provides a better visualization of this deep and narrow surgical field. Bottom left: an operative view with a typical aspect of chordoma, soft purplish tissue (white arrow). Bottom right, the postoperative MRI showing a macroscopic complete removal.

\subsubsection{Infratemporal and pterygopalatine fossas}

Herein, the endonasal approach competes with the usual transfacial approaches like Lefort I to remove tumors in this area (paragangliomas, shwannomas, meningiomas, juvenile nasopharyngeal angiofibromas) (figure 22). This region represents the lateral and inferior limits of endoscopic endonasal approaches with issues related to the multiples branches of the external carotid artery and the trigeminal nerve (Rivero-Serrano et al., 2010; Robinson et al., 2005). 


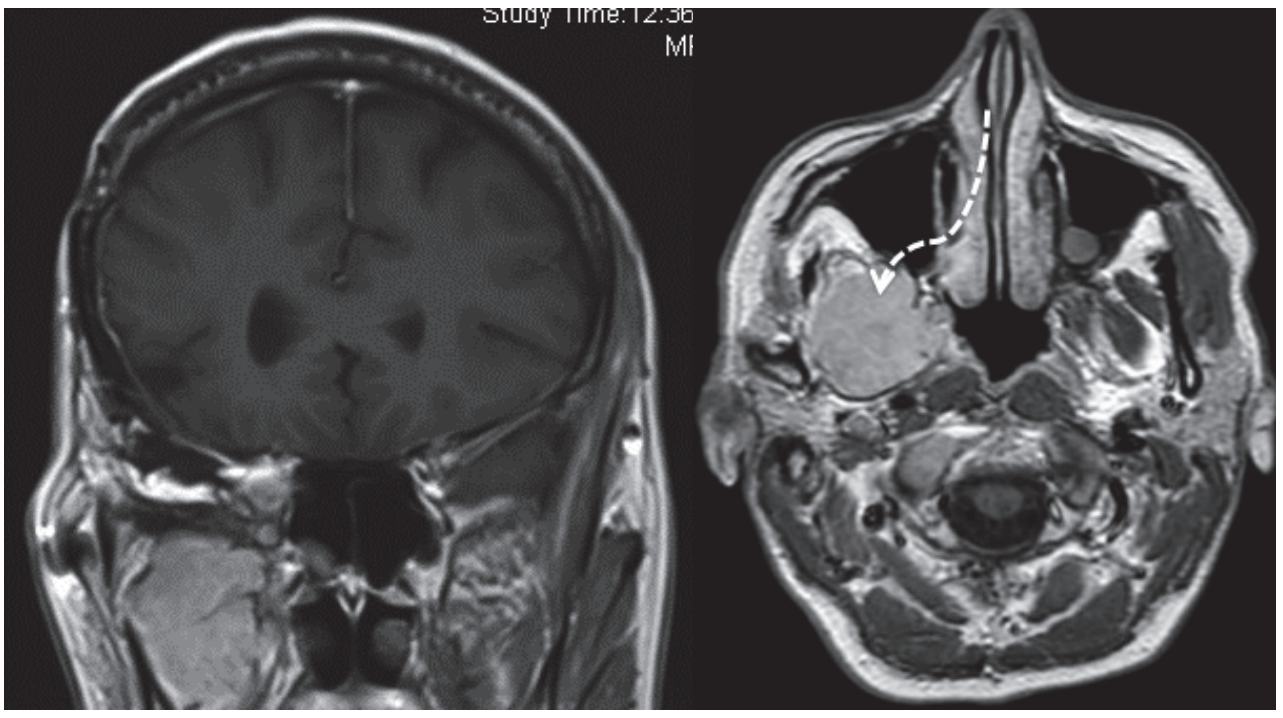

Fig. 22. Example of an extension of a sphenocavernous meningioma into the pterygopalatine fossa. Opening the maxillary sinus by an endonasal route will give a direct access to the lesion (white dotted arrow). It is a variant of the classic Lefort I approach.

\section{Complications}

\subsection{Nasal morbidity}

EESBS is constantly associated with postoperative nasal morbidity including mainly nasal crusting and blocked nose sensation lasting for the first few weeks. The intensity of these symptoms varies from one patient to another, and is usually moderate for pituitary surgery and perfectly managed by local treatments given to patients on discharge from hospital. Nasal consequences of extended approaches are far more complicated, with frequent chronic crusting rhinosinusitis. Indeed in such approaches, turbinectomies and wide sinus aperture impair the nasal airflow which leads to crusting and obstruction. With the spread of these kinds of approaches, many teams are studying the postoperative quality of life using questionnaires such as the SNOT-22 (Sino-Nasal Outcome Test-22) and the anterior skull base questionnaire. Nasal crusting remains the most frequent postoperative complaint while no risk factors have been identified $(98 \%$ of the patients had nasal crusting at one month in Almeida's series). According to Almeida et al., the use of nasoseptal flap for skull base closure is not a significant risk factor of nasal morbidity (de Almeida et al., 2011).

Patients have to be informed preoperatively of this nasal morbidity and particularly the high rate of nasal crusting and possible loss of smell. They should also know that these morbidities are transitional in almost all cases and will improve within 3 to 6 months postoperatively. A postoperative nasal care including sinus humidification and saline irrigation is highly recommended.

Postoperative infectious sphenoid sinusitis may occur in about $2 \%$ of patients, while it can reach $9 \%$ in microsurgical series of pituitary adenomas. A large opening of the sphenoid sinus and a lesser use of artificial packing material within the sphenoid sinus may prevent these infections (Balaker et al., 2010). 


\subsection{CSF leak and meningitis}

CSF leak is the most common complication during endoscopic endonasal approaches to the skull base, with initial high rates decreasing progressively with the learning curve and the closure methods with pediculated flaps. Higher experience in pituitary surgery means rarer CSF leaks, less than 5\% (Messerer et al., 2011). Obviously, extensive approaches involving the anterior skull base are more likely to lead to per and postoperative CSF leaks. We also experienced more frequent CSF leaks for planum meningiomas than for other types of tumors. A postoperative leakage was observed in $15.9 \%$ of the 800 patients treated by Kassam et al., but for anterior skull base meningiomas it can reach up to $50 \%$ of cases (Kassam et al., 2010). An accurate multilayer closure of the skull base is of a paramount importance to avoid postoperative CSF leaks, especially when a peroperative leak is observed. The use of pedicle flaps dramatically decreased the rate of these postoperative CSF leaks (Hadad et al., 2006; Kassam et al., 2005).

Postoperative infection risk is comparable to intracranial open skull base surgery with a rate reaching $1.8 \%$ of patients. Risk factors of meningitis are mainly peroperative CSF leaks and postoperative external ventricular or lumbar drains (Gondim et al., 2010, Kono et al., 2010).

\subsection{Vascular complications}

Early or delayed nasal hemorrhages may occur postoperatively in up to $7 \%$ of patients. These hemorrhages related to small mucosal arteries, are usually of small volume and respond easily to transitory nasal tamponade. An injury or insufficient coagulation of branches of the sphenopalatine artery in the sphenoethmoidal recess may rarely lead to important potentially life-threatening epistaxis, requiring reoperation and/or endovascular management (Gondim et al., 2010).

An internal carotid artery injury is a striking peroperative complication. This artery may be encased within an invasive skull base tumor as well as in redo surgeries, conditions in which neuronavigation and microdoppler probe are very useful tools. In such difficult cases of Meckel's cave or cavernous sinus surgery, a preoperative angiogram should be done and an extra-intracranial anastomosis discussed in the case of a non-functional Willis polygon.

One must be particularly aware of "kissing" carotid arteries sometimes observed in acromegalic patients.

Pseudoaneurysms and carotid-cavernous fistulas may result months or years after aggressive tumoral dissection and curettage within the cavernous sinuses (Cappabianca et al., 2001).

A careful analysis of preoperative MRI and eventually angiographic studies is mandatory to avoid such dramatic complications (Solares et al., 2010).

\subsection{Endocrinological issues}

Hydro-electrolytic balance monitoring is compulsory during the early postoperative course in order to detect diabetes insipidus, either transient (2-20\% in pituitary adenomas) or permanent $(1-5 \%)$, usually secondary to surgical manipulation or injury to posterior pituitary gland and/or pituitary stalk.

Postoperative anterior pituitary dysfunction may occur in $13 \%$ to one third of patients with pituitary adenomas managed endoscopically, depending of the preoperative condition (Messerer et al., 2011). Endocrine results are clearly poorer for craniopharyngiomas while unclear or sparse for the other sellar tumors. 


\subsection{Ocular complications}

Orbital hemorrhages may be caused by an injury to the ethmoidal artery during an endoscopic endonasal approach, and subsequent retraction of this artery within the orbit may occur. In such a case, an emergency orbital decompression can be needed (Charalampaki et al., 2009). Elsewhere, a direct injury to the globe or to the medial rectus muscle or even to the nasolacrymal duct may occur, specially during the initial learning curve (May et al., 1994).

\subsection{Pituitary apoplexy}

Postoperative apoplexy usually occurs when an obvious suprasellar adenomatous remnant is left in place. The major risk of this complication is the acute compression of the visual apparatus, acute pituitary insufficiency and obstructive hydrocephalus. Emergent reoperation may be necessary, either by the same endonasal route or intra-cranial approach according to apoplexy configuration.

\section{Closure techniques: The multilayer technique as key point}

The CSF leak is the main issue of EESBS, thus making closure time as important as the tumor removal itself. Many studies have been pusblished on this topic, each progress leading to a decrease in the percentage of postoperative CSF leak. One must understand that each layer has to be rebuilt (figure 23).

The arachnoid plane can be reinforced with intradural injection of fibrin glue and/or using a soft inlay graft covering the dural aperture. Extraduraly, the removed dura mater has to be replaced by a substitute. We prefer a bio-absorbable one as we experienced 3 cases of sellar space-occupying infections following pituitary surgery, where the dural plane had been rebuilt with a non-resorbable dural substitute. The bone plane is recreated using synthetic material (titanium plate) or using autologous bone (ie what we called the bone flap previously). This latter has our preference, as the long term tolerance of synthetic material is not known. The turbinates can be also used specially in locations where a bone flap cannot be done (clivus for instance).

The bone flap has to be covered after its repositionning. Autologous but inert material such as fat graft and fascia lata alone are disapointing with 30 to $50 \%$ of postoperative CSF leaks (Kassam et al., 2008). Vascular pediculated flaps (figure 24) is the biggest advance in endoscopic surgery leading to a dramatic decrease in the rate of CSF leak from $30 \%$ to around 4\% (Kassam et al., 2008). The most easy to prepare is the nasoseptal flap (Hadad et al., 2006) but many other flaps are possible: pericranial, buccinator and temporoparietal fascia flap (Caicedo-Granados et al., 2010 ; Patel et al., 2010 ; Rivera-Serrano et al., 2010). To reinforce the watertight of the reconstruction, a fibrin glue is applied all over the bone and mucosa. The sinus cavities are therefore filled up with fat embedded in glue.

When repairing the anterior skull base, the risk of graft migration is higher during the first few days. A balloon can be used in prevention, as a support kept in place for 3 or 5 days. This must not be used in patients where visual function cannot be monitored closely.

Finally, CSF drainage to decrease intracranial pressure is still being discussed. External drain should be avoided because of the risk of contamination but we perform 3 to 5 postoperative lumbar punctures for high-risk surgeries such as anterior skull base, meningiomas and intraventricular surgeries. 


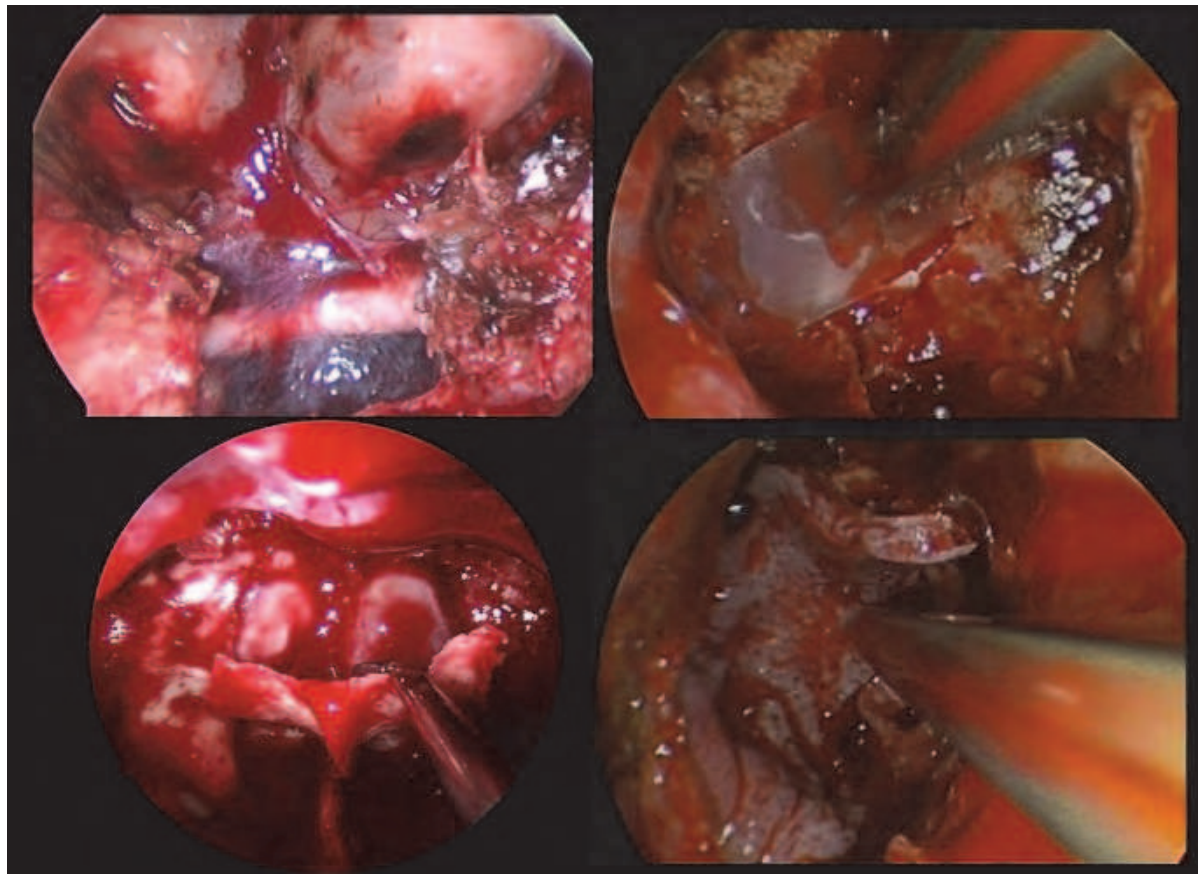

Fig. 23. Multilayered closure. Arachnoid with fibrin glue (top left), dura mater substitute (top right), bone flap positioning (bottom left) and mucosa flap( bottom right).

\section{Controversies and limits: Extended endonasal approaches versus trans- eyebrow keyhole endoscopic approaches for anterior skull base tumors}

If no one disputes the benefit of the endonasal endoscopic approach for retrochiasmatic parasellar or clival tumors, its use for anterior skull base tumors is still being discussed (i.e. from the cribriform plate to the tuberculum of the sella) (de Devitiis et al., 2008).

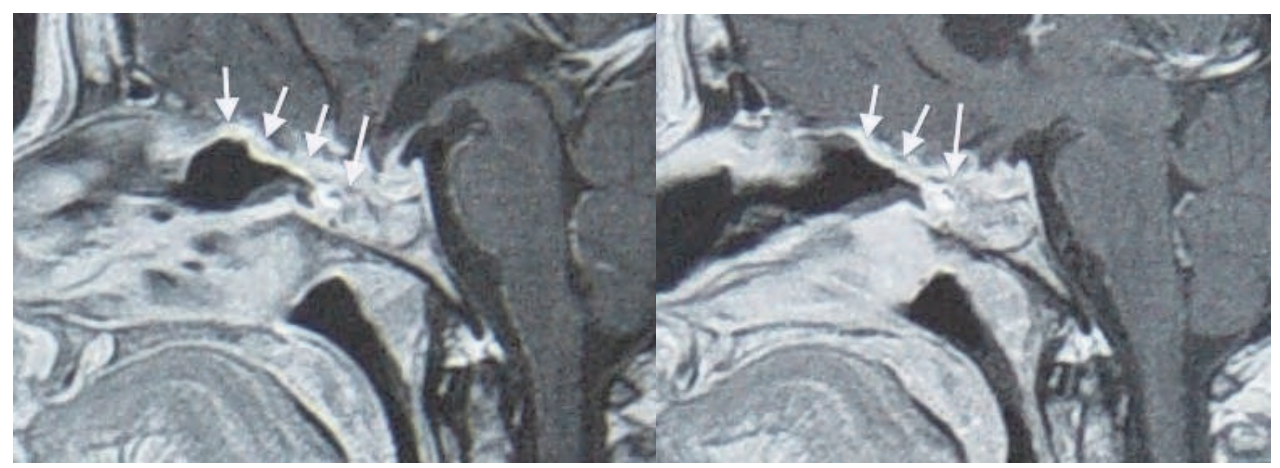

Fig. 24. Complete removal of planum meningioma. Postoperative MRI (sagittal T1 weighted sequence with gadolinium). The nasoseptal flap used to reconstruct the skull base is clearly visible enhanced after contrast injection (arrows). 
Indeed, the endonasal route presents many advantages: no brain retraction, a useful suppression of the blood supplies of the tumour always interesting specially for meningiomas and a better control of the inferomedial part of the optic canal. Other arguments argue against the endonasal approach in case of anterior skull base tumors.

The first one is a risk of CSF fistula higher than in others locations as the dura mater and bone graft might migrate down more easily when repairing the anterior skull base compared to middle cranial base. As reported by others (de devitiis et al. 2008), in our own experience of extended approaches (more than 100 cases to date comprising all locations), around half of the procedures done for anterior skull base (20 cases) was complicated by postoperative CSF leaks. Even though, we obtain clearly better results when using the bone and nasal flaps, this point was the first to exhort us to find an alternative mini-invasive keyhole approach.

The second one was the absence of control of the tumor margins when tumors grow over the optic nerves and carotid arteries, a common feature of meningiomas that usually extend largely on the anterior skull base. This may lead to tumor remnant (figure 25). On that particular point, it will be interesting to consider the frequency of tumor recurrence in series of anterior skull base meningiomas operated from below with long-term follow up before giving a definitive conclusion.

Finally, anterior skull tumors without olfactory impairment are another reason to choose the intracranial instead of the endonasal route. There are, of course, better chances to preserve olfactory nerves by an intracranial route.

The supraorbital trans-eyebrow approach was initially introduced for vascular clipping or skull base tumors removal primarily with the use of microscope (Reisch et al., 2003).

Since 2010, we use this keyhole approach purely with the endoscope instead of microscope. This allows a real keyhole approach (bone aperture of $2 \mathrm{~cm}$ ), the straight and angle endoscopes give a panoramic view of the entire anterior skull base but also of the opticocarotid recess and of the medial part of the optic canal (figure 26). With such a technique, we are able to remove meningiomas with as uneventful postoperative course as after endonasal endoscopic approaches (even with shorter hospital stay), without the risk of CSF fistula.

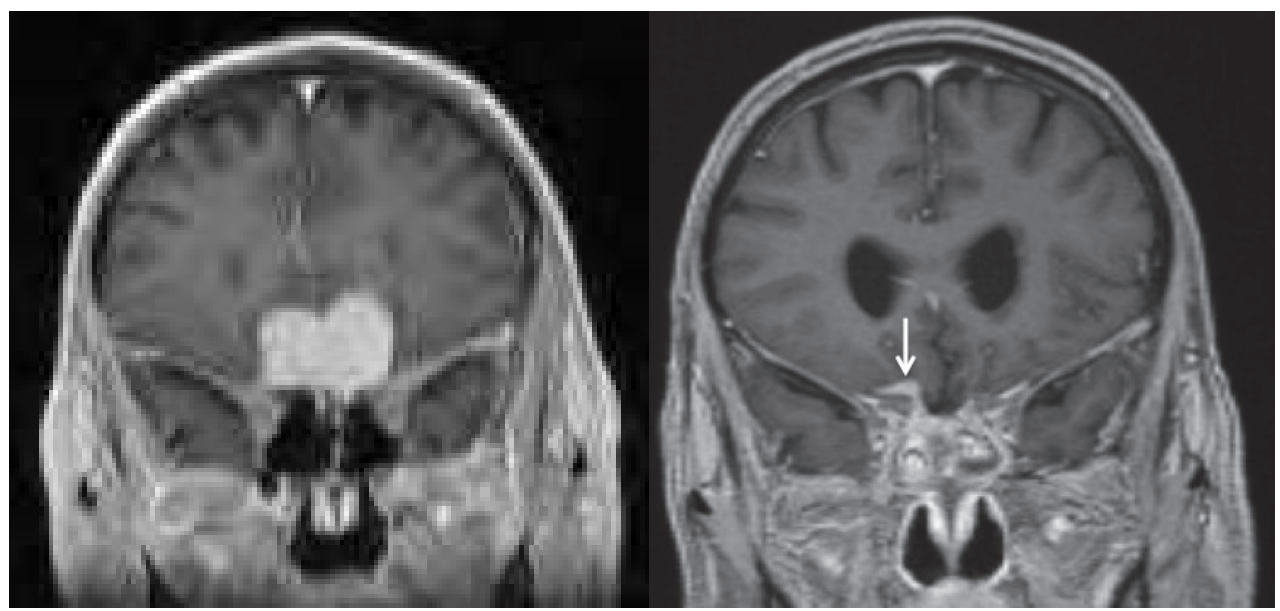

Fig. 25. Example of an anterior skull base meningioma removed from below. The postoperative MRI clearly indicated a tumor remnant on the top of the right clinoidal process (white arrow) that has not been seen during the endonasal route. 


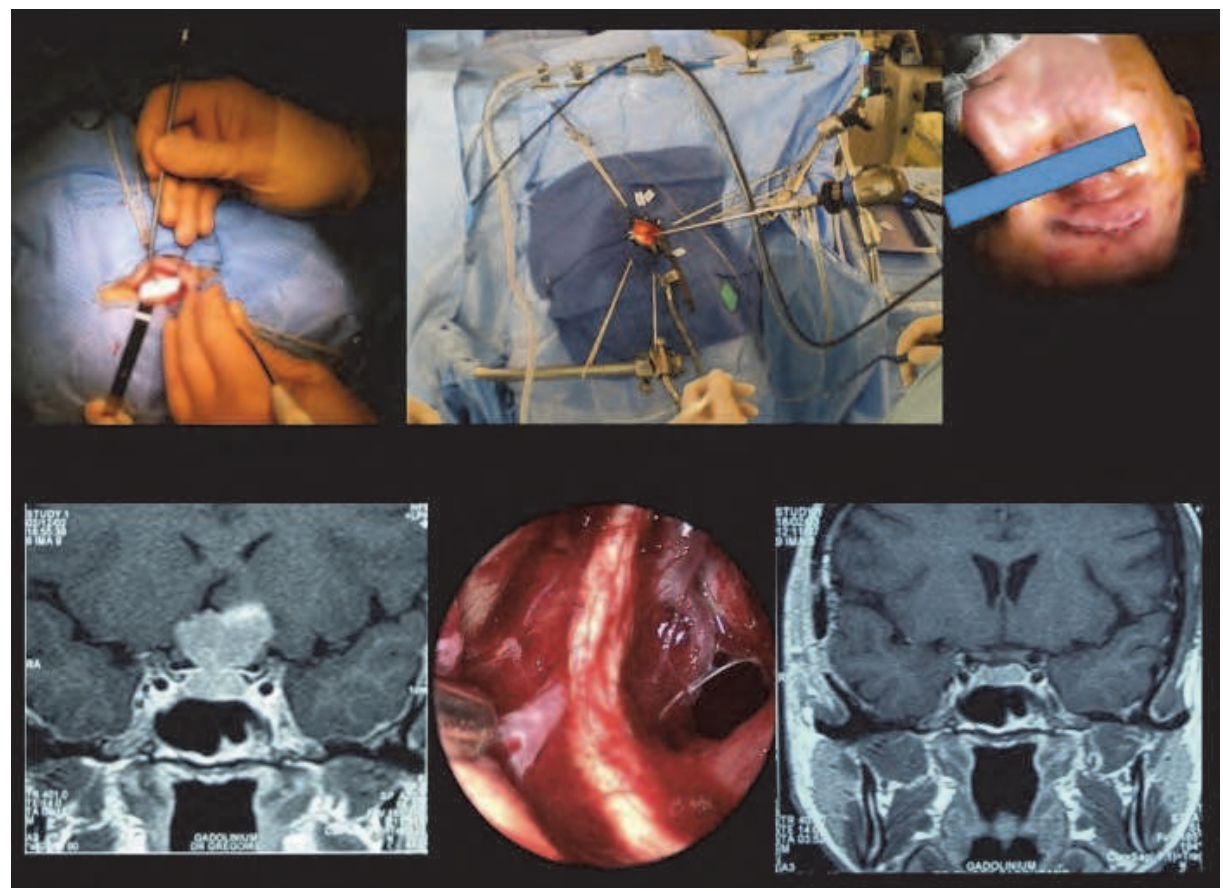

Fig. 26. Eyebrow supraorbital surgery for a suprasellar meningioma. This keyhole approach (frontal craniotomy of $2 \mathrm{~cm}$, top left) can be done with the endoscope instead of the microscope (middle top). Angled endoscopes give the possibility of exploring all the corners of the surgical field like the medial opticocarotid recess (middle bottom) but also the entire anterior skull base, what cannot be done with the endonasal route.

For the authors, this mini invasive endoscopic eyebrow approach should be considered for large tumors grown beyond the suprasellar carotid arteries but also for small anteriorly based tumors, thus avoiding any CSF leak.

\section{Conclusion}

The part of the endoscopic endonasal approach is getting more and more important in skull base surgery since the beginning of the nineties. Under the impulsion of the Pittsburgh and Neapolitan neurosurgical teams, the last two decades saw an increasing number of publications on that topic either on anatomy or surgical techniques (more than 800 entries on Pubmed using 2 key words, "endoscopy" and "skull base"). Thus, new surgical corridors to approach especially midline skull base tumors have been described.

However, the exact role and indications of the endonasal endoscopic surgery are still being discussed in the absence of large or randomized series. Compared to intracranial microsurgical approaches, the endoscopic endonasal routes offer genuine benefits for pituitary surgery as well as for retrochiasmatic or midline clival tumors. For parasellar lesions, the endonasal endoscopic technique is also interesting to remove or to biopsy Meckel's cave lesions or tumors extending into the cavernous sinus. This will not change 
much the current management of cavernous sinus lesions where most of the time radiotherapy is the treatment of choice and for which no biopsy is required when imaging is typical.

Its use for anterior skull base tumors is more controversial. Indeed, the high percentage of CSF leaks, specially for meningiomas, and the absence of control of the lateral tumour margins raise interrogation about the real benefit of this endonasal approach. In their experience, the authors think that other mini-invasive approaches such as the supraorbital eyebrow one are likely to be more seductive.

To date, the endonasal endoscopic surgery provides interesting and complementary routes for skull base tumors but will not replace the standard intracranial approaches. Large multicentric studies with long-term follow up are being done to define precisely the real indications and benefits of such endonasal surgery. Technical refinements are also expected in a close future using 3D endoscope and robotics (Hanna et al., 2007; Levy et al., 2006; O’Malley \& Weinstein, 2007).

\section{References}

Alfieri A, Jho HD. (2001). Endoscopic endonasal cavernous sinus surgery: an anatomic study. Neurosurgery 48: 827-836; discussion 836-837.

Alfieri A, Jho HD. (2001). Endoscopic endonasal approaches to the cavernous sinus: surgical approaches. Neurosurgery 49: 354-360; discussion 360-362.

Alfieri A, Jho H, Tschabitscher M. (2002). Endoscopic endonasal approach to the ventral cranio-cervical junction: anatomical study. Acta Neurochir (Wien) 144: 219-225; discussion 225.

Alfieri A, Schettino R, Tarfani A, Bonzi O, Rossi GA, Monolo L. (2002). Endoscopic endonasal removal of an intra-suprasellar Rathke's cleft cyst: case report and surgical considerations. Minim Invasive Neurosurg 45: 47-51.

de Almeida JR, Zanation AM, Snyderman CH, Carrau RL, Prevedello DM, Gardner PA, et al. (2009). Defining the nasopalatine line: the limit for endonasal surgery of the spine. Laryngoscope 119: 239-244.

de Almeida JR, Snyderman CH, Gardner PA, Carrau RL, Vescan AD. (2011). Nasal morbidity following endoscopic skull base surgery: A prospective cohort study. Head Neck 33(4):547-51.

Balaker AE, Bergsneider M, Martin NA, Wang MB. (2010). Evolution of sinonasal symptoms following endoscopic anterior skull base surgery. Skull Base 20(4):245-51.

Batra PS, Citardi MJ, Worley S, Lee J, Lanza DC. (2005). Resection of anterior skull base tumors: comparison of combined traditional and endoscopic techniques. Am J Rhinol 19: 521-528.

Caicedo-Granados E, Carrau R, Snyderman CH, Prevedello D, Fernandez-Miranda J, Gardner P, et al. (2010). Reverse rotation flap for reconstruction of donor site after vascular pedicled nasoseptal flap in skull base surgery. Laryngoscope 120: 1550-1552.

Cappabianca P, Alfieri A, de Divitiis E. (1998). Endoscopic endonasal transsphenoidal approach to the sella: towards functional endoscopic pituitary surgery (FEPS). Minim Invasive Neurosurg 41: 66-73. 
Cappabianca P, Briganti F, Cavallo LM, de Divitiis E. (2001). Pseudoaneurysm of the intracavernous carotid artery following endoscopic endonasal transsphenoidal surgery, treated by endovascular approach. Acta Neurochir (Wien) 143: 9596.

Carrau RL, Kassam AB, Snyderman CH. (2001). Pituitary surgery. Otolaryngol. Clin. North Am 34: 1143-1155, ix.

Castelnuovo P, Dallan I, Pistochini A, Battaglia P, Locatelli D, Bignami M. (2007). Endonasal endoscopic repair of Sternberg's canal cerebrospinal fluid leaks. Laryngoscope 117: 345-349.

Castelnuovo P, Dallan I, Bignami M, Pistochini A, Battaglia P, Tschabitscher M. (2008). Endoscopic endonasal management of petroclival cerebrospinal fluid leaks: anatomical study and preliminary clinical experience. Minim Invasive Neurosurg 51: 336-339.

Castelnuovo P, Dallan I, Battaglia P, Bignami M. (2010). Endoscopic endonasal skull base surgery: past, present and future. Eur Arch Otorhinolaryngol 267: 649-663.

Caton R. (1893). Notes of a case of acromegaly treated by operation. Br Med J 2: 14211423.

Cavallo LM, Cappabianca P, Messina A, Esposito F, Stella L, de Divitiis E, et al. (2007). The extended endoscopic endonasal approach to the clivus and cranio-vertebral junction: anatomical study. Childs Nerv Syst 23: 665-671.

Cavallo LM, Prevedello DM, Solari D, Gardner PA, Esposito F, Snyderman CH, et al. (2009). Extended endoscopic endonasal transsphenoidal approach for residual or recurrent craniopharyngiomas. J Neurosurg 111: 578-589.

Charalampaki P, Ayyad A, Kockro RA, Perneczky A. (2009). Surgical complications after endoscopic transsphenoidal pituitary surgery. J Clin Neurosci. 16(6):786-9.

Cebula H, Lahlou A, De Battista JC, Debry C, Froelich S. (2010). [Endoscopic approaches to the orbit]. Neurochirurgie 56: 230-235.

Crockard HA. (1985). The transoral approach to the base of the brain and upper cervical cord. Ann R Coll Surg Engl 67: 321-325.

Cushing H.(1909). III. Partial Hypophysectomy for Acromegaly: With Remarks on the Function of the Hypophysis. Ann. Surg 50: 1002-1017.

Dandy W. (1926). Pneumocephalus (intracranial pneumatocoele or aerocoele). Arch Surg 12: 949-982.

Dandy W. (1932). Practice of surgery. Dans: The brain. Hagerstown; p. 247-252.

de Divitiis E, Cappabianca P, Cavallo LM. (2002). Endoscopic transsphenoidal approach: adaptability of the procedure to different sellar lesions. Neurosurgery 51: 699-705; discussion 705-707.

de Divitiis E, Esposito F, Cappabianca P, Cavallo LM, de Divitiis O, Esposito I. (2008). Endoscopic transnasal resection of anterior cranial fossa meningiomas. Neurosurg Focus 25(6): E8.

Dehdashti AR, Ganna A, Karabatsou K, Gentili F. (2008). Pure endoscopic endonasal approach for pituitary adenomas: early surgical results in 200 patients and comparison with previous microsurgical series. Neurosurgery. 62(5):1006-15; discussion 1015-7. 
D'Haens J, Van Rompaey K, Stadnik T, Haentjens P, Poppe K, Velkeniers B. (2009). Fully endoscopic transsphenoidal surgery for functioning pituitary adenomas: a retrospective comparison with traditional transsphenoidal microsurgery in the same institution. Surg Neurol. 72(4):336-40. Epub 2009 Jul 14.

Draf W. (1973). [Clinical value of sinus endoscopy (author's transl)]. Z Laryngol Rhinol Otol 52: 890-896.

Fernandez-Miranda JC, Gardner PA, Prevedello DM, Kassam AB. (2009). Expanded endonasal approach for olfactory groove meningioma. Acta Neurochir (Wien) 151: 287-288; author reply 289-290.

Frank G, Pasquini E. (2003). Approach to the cavernous sinus. Dans: Endoscopic endonasal transsphenoidal surgery. Vienna: de Devitiis E, Cappabianca P; p. 159-175.

Frank G, Pasquini E, Farneti G, Mazzatenta D, Sciarretta V, Grasso V, et al. (2006). The endoscopic versus the traditional approach in pituitary surgery. Neuroendocrinology 83: 240-248.

Gardner PA, Kassam AB, Rothfus WE, Snyderman CH, Carrau RL. (2008). Preoperative and intraoperative imaging for endoscopic endonasal approaches to the skull base. Otolaryngol. Clin. North Am 41: 215-230, vii.

Gardner PA, Kassam AB, Snyderman CH, Carrau RL, Mintz AH, Grahovac S, Stefko S. (2008). Outcomes following endoscopic, expanded endonasal resection of suprasellar craniopharyngiomas: a case series. J. Neurosurg 109: 6-16.

Gardner PA, Prevedello DM, Kassam AB, Snyderman CH, Carrau RL, Mintz AH. (2008). The evolution of the endonasal approach for craniopharyngiomas. J. Neurosurg 108: 1043-1047.

Gondim JA, Almeida JP, Albuquerque LA, Schops M, Gomes E, Ferraz T, Sobreira W, Kretzmann MT. (2010). Endoscopic endonasal approach for pituitary adenoma: surgical complications in 301 patients. Pituitary. 2010 Dec 23. [Epub ahead of print]

Grant JA. (1996). Victor Darwin Lespinasse: a biographical sketch. Neurosurgery 39: 12321233.

Griffith AJ, Terrell JE. (1996). Transsphenoid endoscopic management of petrous apex cholesterol granuloma. Otolaryngol Head Neck Surg 114: 91-94.

Guiot G, Bouche J, Hertzog E, Vourc'h G, Hardy J. (1963). [Hypophysectomy by transsphenoidal route.]. Ann Radiol (Paris) 6: 187-192.

Guiot J, Rougerie J, Fourestier M, Fournier A, Comoy C, Vulmiere J, et al. (1963). [Intracranial endoscopic explorations.]. Presse Med 71: 1225-1228.

Hadad G, Bassagasteguy L, Carrau RL, Mataza JC, Kassam A, Snyderman CH, et al. (2006). A novel reconstructive technique after endoscopic expanded endonasal approaches: vascular pedicle nasoseptal flap. Laryngoscope 116: 18821886.

Hanna EY, Holsinger C, DeMonte F, Kupferman M. (2007). Robotic endoscopic surgery of the skull base: a novel surgical approach. Arch. Otolaryngol. Head Neck Surg 133: 1209-1214.

Har-El G. (2005). Endoscopic transnasal transsphenoidal pituitary surgery--comparison with the traditional sublabial transseptal approach. Otolaryngol. Clin. North Am 38: 723735 . 
Hardy J. (2010). [History of pituitary surgery]. Neurochirurgie 56: 358-362.

Herr HW. (2006). Max Nitze, the cystoscope and urology. J. Urol 176: 1313-1316.

Higgins TS, Courtemanche C, Karakla D, Strasnick B, Singh RV, Koen JL, et al. (2008). Analysis of transnasal endoscopic versus transseptal microscopic approach for excision of pituitary tumors. Am J Rhinol 22: 649-652.

Hirsch O. (1952). Successful closure of cerebrospinal fluid rhinorrhea by endonasal surgery. AMA Arch Otolaryngol 56: 1-12.

Jankowski R, Auque J, Simon C, Marchal JC, Hepner H, Wayoff M. (1992). Endoscopic pituitary tumor surgery. Laryngoscope 102: 198-202.

Jho HD, Carrau RL, McLaughlin ML, Somaza SC. (1996). Endoscopic transsphenoidal resection of a large chordoma in the posterior fossa. Case report. Neurosurg Focus 1: e3; discussion $1 \mathrm{p}$ following e3.

Jho HD, Carrau RL. (1997). Endoscopic endonasal transsphenoidal surgery: experience with 50 patients. J. Neurosurg 87: 44-51.

Kassam A, Carrau RL, Snyderman CH, Gardner P, Mintz A. (2005). Evolution of reconstructive techniques following endoscopic expanded endonasal approaches. Neurosurg Focus 19: E8.

Kassam AB, Gardner P, Snyderman C, Mintz A, Carrau R. (2005). Expanded endonasal approach: fully endoscopic, completely transnasal approach to the middle third of the clivus, petrous bone, middle cranial fossa, and infratemporal fossa. Neurosurg Focus 19: E6.

Kassam AB, Mintz AH, Gardner PA, Horowitz MB, Carrau RL, Snyderman CH. (2006). The expanded endonasal approach for an endoscopic transnasal clipping and aneurysmorrhaphy of a large vertebral artery aneurysm: technical case report. Neurosurgery 59: ONSE162-165; discussion ONSE162-165.

Kassam AB, Thomas AJ, Zimmer LA, Snyderman CH, Carrau RL, Mintz A, et al. (2007). Expanded endonasal approach: a fully endoscopic completely transnasal resection of a skull base arteriovenous malformation. Childs Nerv Syst 23: 491-498.

Kassam AB, Gardner PA, Mintz A, Snyderman CH, Carrau RL, Horowitz M. (2007). Endoscopic endonasal clipping of an unsecured superior hypophyseal artery aneurysm. Technical note. J. Neurosurg 107: 1047-1052.

Kassam AB, Gardner PA, Snyderman CH, Carrau RL, Mintz AH, Prevedello DM. (2008). Expanded endonasal approach, a fully endoscopic transnasal approach for the resection of midline suprasellar craniopharyngiomas: a new classification based on the infundibulum. J. Neurosurg 108: 715-728.

Kassam AB, Prevedello DM, Carrau RL, Snyderman CH, Gardner P, Osawa S, et al. (2009). The front door to meckel's cave: an anteromedial corridor via expanded endoscopic endonasal approach- technical considerations and clinical series. Neurosurgery 64: 71-82; discussion 82-83.

Kassam AB, Prevedello DM, Carrau RL, Snyderman CH, Thomas A, Gardner P, Zanation A, Duz B, Stefko ST, Byers K, Horowitz MB. (2010). Endoscopic endonasal skull base surgery: analysis of complications in the authors' initial 800 patients. J Neurosurg. 2010 Dec 17. [Epub ahead of print]

Kassis S, De Battista JC, Raverot G, Jacob M, Simon E, Rabilloud M, Froehlich P, Trouillas J, Borson-Chazot F, Perrin G, Jouanneau E. (2009). [Endoscopy versus microsurgery: 
results in a consecutive series of nonfunctioning pituitary adenomas]. Neurochirurgie 55: 607-615.

Kono Y, Prevedello DM, Snyderman CH, Gardner PA, Kassam AB, Carrau RL, Byers KE. (2011). One thousand endoscopic skull base surgical procedures demystifying the infection potential: incidence and description of postoperative meningitis and brain abscesses. Infect Control Hosp Epidemiol. 32(1):77-83. Epub 2010 Dec 1.

Landolt AM. (2001). History of pituitary surgery from the technical aspect. Neurosurg. Clin. N. Am 12: 37-44, vii-viii.

Leng LZ, Anand VK, Hartl R, Schwartz TH. (2009). Endonasal endoscopic resection of an os odontoideum to decompress the cervicomedullary junction: a minimal access surgical technique. Spine 34: E139-143.

Levy ML, Nguyen A, Aryan H, Jandial R, Meltzer HS, Apuzzo MLJ. (2006). Robotic virtual endoscopy: development of a multidirectional rigid endoscope. Neurosurgery 59: ONS134-141; discussion ONS134-141.

Léger P. (2004). [Antonin Jean Desormeaux]. Prog. Urol 14: 1231-1238.

Lindholm J. (2007). A century of pituitary surgery: Schloffer's legacy. Neurosurgery 61: 865867; discussion 867-868.

Litynski GS. (1999). Endoscopic surgery: the history, the pioneers. World J Surg 23: 745753.

Liu JK, Das K, Weiss MH, Laws ER, Couldwell WT. (2001). The history and evolution of transsphenoidal surgery. J. Neurosurg 95: 1083-1096.

Magrini S, Pasquini E, Mazzatenta D, Mascari C, Galassi E, Frank G. (2008). Endoscopic endonasal odontoidectomy in a patient affected by Down syndrome: technical case report. Neurosurgery 63: E373-374; discussion E374.

Martin TJ, Loehrl TA. (2007). Endoscopic CSF leak repair. Curr Opin Otolaryngol Head Neck Surg 15: 35-39.

May M, Levine HL, Mester SJ, Schaitkin B. (1994). Complications of endoscopic sinus surgery: analysis of 2108 patients--incidence and prevention. Laryngoscope 104: 1080-1083.

Messerer M, De Battista JC, Raverot G, Kassis S, Dubourg J, Lapras V, Trouillas J, Perrin G, Jouanneau E. (2011). Evidence of improved surgical outcome following endoscopy for nonfunctioning pituitary adenoma removal. Neurosurg Focus. 30(4):E11.

Nayak JV, Gardner PA, Vescan AD, Carrau RL, Kassam AB, Snyderman CH. (2007). Experience with the expanded endonasal approach for resection of the odontoid process in rheumatoid disease. Am J Rhinol 21: 601-606.

Nyquist GG, Anand VK, Mehra S, Kacker A, Schwartz TH. (2010). Endoscopic endonasal repair of anterior skull base non-traumatic cerebrospinal fluid leaks, meningoceles, and encephaloceles. J. Neurosurg 113: 961-966.

O'Malley BW, Weinstein GS. (2007). Robotic skull base surgery: preclinical investigations to human clinical application. Arch. Otolaryngol. Head Neck Surg 133: 1215-1219. 
Patel MR, Shah RN, Snyderman CH, Carrau RL, Germanwala AV, Kassam AB, et al. (2010). Pericranial flap for endoscopic anterior skull-base reconstruction: clinical outcomes and radioanatomic analysis of preoperative planning. Neurosurgery 66: 506-512; discussion 512.

Pollock JR, Akinwunmi J, Scaravilli F, Powell MP. (2003). Transcranial surgery for pituitary tumors performed by Sir Victor Horsley. Neurosurgery 52: 914-925; discussion 925926.

Prevedello DM, Pinheiro-Neto CD, Fernandez-Miranda JC, Carrau RL, Snyderman CH, Gardner PA, Kassam AB. (2010). Vidian nerve transposition for endoscopic endonasal middle fossa approaches. Neurosurgery. 67(2 Suppl Operative):47884.

Ramachandran R, Singh PM, Batra M, Pahwa D. (2011). Anaesthesia for endoscopic endonasal surgery. Trends in Anaesthesia and Critical Care 1:79-83

Rathert P. (1967). Max Nitze (1848-1906). Invest Urol 5: 327-330.

Reisch R, Perneczky A, Filippi R. (2003). Surgical technique of the supraorbital key-hole craniotomy. Surg Neurol 59: 223-227.

Reuter M. (2000). The historical development of endophotography. World J Urol 18: 299302.

Rivera-Serrano CM, Oliver CL, Sok J, Prevedello DM, Gardner P, Snyderman CH, et al. (2010). Pedicled facial buccinator (FAB) flap: a new flap for reconstruction of skull base defects. Laryngoscope 120: 1922-1930.

Rivera-Serrano CM, Terre-Falcon R, Fernandez-Miranda J, Prevedello D, Snyderman CH, Gardner P, Kassam A, Carrau RL. (2010). Endoscopic endonasal dissection of the pterygopalatine fossa, infratemporal fossa, and post-styloid compartment. Anatomical relationships and importance of eustachian tube in the endoscopic skull base surgery. Laryngoscope. 120 Suppl 4:S244.

Robinson S, Patel N, Wormald PJ. (2005). Endoscopic management of benign tumors extending into the infratemporal fossa: a two-surgeon transnasal approach. Laryngoscope 115: 1818-1822.

Schaberg MR, Anand VK, Schwartz TH, Cobb W. (2010). Microscopic versus endoscopic transnasal pituitary surgery. Curr Opin Otolaryngol Head Neck Surg 18: 814.

Schwartz TH, Fraser JF, Brown S, Tabaee A, Kacker A, Anand VK. (2008). Endoscopic cranial base surgery: classification of operative approaches. Neurosurgery 62: 9911002; discussion 1002-1005.

Snyderman C, Kassam A, Carrau R, Mintz A, Gardner P, Prevedello DM. (2007). Acquisition of surgical skills for endonasal skull base surgery: a training program. Laryngoscope 117: 699-705.

Snyderman CH, Carrau RL, Kassam AB, Zanation A, Prevedello D, Gardner P, et al. (2008). Endoscopic skull base surgery: principles of endonasal oncological surgery. J Surg Oncol 97: 658-664.

Solares CA, Ong YK, Carrau RL, Fernandez-Miranda J, Prevedello DM, Snyderman CH, et al. (2010). Prevention and management of vascular injuries in endoscopic 
surgery of the sinonasal tract and skull base. Otolaryngol. Clin. North Am 43: 817-825.

Suriano M, De Vincentiis M, Colli A, Benfari G, Mascelli A, Gallo A. (2007). Endoscopic treatment of esthesioneuroblastoma: a minimally invasive approach combined with radiation therapy. Otolaryngol Head Neck Surg 136: 104-107.

Wigand ME. (1981). Transnasal ethmoidectomy under endoscopical control. Rhinology 19: 715. 


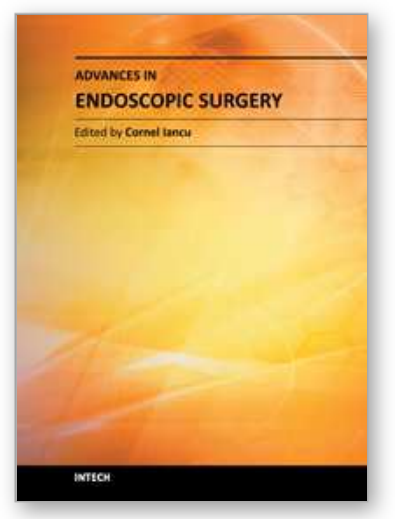

\author{
Advances in Endoscopic Surgery \\ Edited by Prof. Cornel lancu
}

ISBN 978-953-307-717-8

Hard cover, 444 pages

Publisher InTech

Published online 25, November, 2011

Published in print edition November, 2011

Surgeons from various domains have become fascinated by endoscopy with its very low complications rates, high diagnostic yields and the possibility to perform a large variety of therapeutic procedures. Therefore during the last 30 years, the number and diversity of surgical endoscopic procedures has advanced with many new methods for both diagnoses and treatment, and these achievements are presented in this book. Contributing to the development of endoscopic surgery from all over the world, this is a modern, educational, and engrossing publication precisely presenting the most recent development in the field. New technologies are described in detail and all aspects of both standard and advanced endoscopic maneuvers applied in gastroenterology, urogynecology, otorhinolaryngology, pediatrics and neurology are presented. The intended audience for this book includes surgeons from various specialities, radiologists, internists, and subspecialists.

\title{
How to reference
}

In order to correctly reference this scholarly work, feel free to copy and paste the following:

Jouanneau Emmanuel, Messerer Mahmoud and Berhouma Moncef (2011). Endoscopic Endonasal Skull Base Surgery: Current State of the Art and Future Trends, Advances in Endoscopic Surgery, Prof. Cornel lancu (Ed.), ISBN: 978-953-307-717-8, InTech, Available from: http://www.intechopen.com/books/advances-inendoscopic-surgery/endoscopic-endonasal-skull-base-surgery-current-state-of-the-art-and-future-trends

\section{INTECH}

open science | open minds

\author{
InTech Europe \\ University Campus STeP Ri \\ Slavka Krautzeka 83/A \\ 51000 Rijeka, Croatia \\ Phone: +385 (51) 770447 \\ Fax: +385 (51) 686166 \\ www.intechopen.com
}

\author{
InTech China \\ Unit 405, Office Block, Hotel Equatorial Shanghai \\ No.65, Yan An Road (West), Shanghai, 200040, China \\ 中国上海市延安西路65号上海国际贵都大饭店办公楼405单元 \\ Phone: +86-21-62489820 \\ Fax: +86-21-62489821
}


(C) 2011 The Author(s). Licensee IntechOpen. This is an open access article distributed under the terms of the Creative Commons Attribution 3.0 License, which permits unrestricted use, distribution, and reproduction in any medium, provided the original work is properly cited. 